\title{
MULTIPLE BUT ASYMMETRIC BANK FINANCING: THE CASE OF RELATIONSHIP LENDING
}

\author{
RALF ELSAS \\ FRANK HEINEMANN \\ MARCEL TYRELL
}

CESIFO WORKING PAPER NO. 1251

CATEGORY 6: MONETARY POLICY AND INTERNATIONAL FINANCE

August 2004

\footnotetext{
An electronic version of the paper may be downloaded

- from the SSRN website:

www.SSRN.com

- from the CESifo website:

www.CESifo.de
} 


\title{
MULTIPLE BUT ASYMMETRIC BANK FINANCING: THE CASE OF RELATIONSHIP LENDING
}

\begin{abstract}
Empirical evidence suggests that even those firms presumably most in need of monitoringintensive financing (young, small, and innovative firms) have a multitude of bank lenders, where one may be special in the sense of relationship lending. However, theory does not tell us a lot about the economic rationale for relationship lending in the context of multiple bank financing.

To fill this gap, we analyze the optimal debt structure in a model that allows for multiple but asymmetric bank financing. The optimal debt structure balances the risk of lender coordination failure from multiple lending and the bargaining power of a pivotal relationship bank. We show that firms with low expected cash-flows or low interim liquidation values of assets prefer asymmetric financing, while firms with high expected cash-flow or high interim liquidation values of assets tend to finance without a relationship bank.
\end{abstract}

JEL Code: G21, G33, G78.

Keywords: relationship lending, multiple bank financing, lender coordination.

\author{
Ralf Elsas \\ Department of Finance \\ Goethe-University Frankfurt \\ Mertonstr. 17-21 \\ 60054 Frankfurt \\ Germany \\ r.elsas@em.uni-frankfurt.de
}

\author{
Frank Heinemann \\ Seminar of Macroeconomics \\ University of Munich \\ Ludwigstr. $28 R G$ \\ 80539 Munich
}

Germany

frank.heinemann@lrz-uni-muenchen.de

\author{
Marcel Tyrell \\ Department of Finance \\ Goethe-University Frankfurt \\ Mertonstr. 17-21 \\ 60054 Frankfurt \\ Germany \\ tyrell@wiwi.uni-frankfurt.de
}

We thank, without implicating, Christina Bannier and seminar participants at GoetheUniversität Frankfurt, and University of Münster for helpful comments. Ralf Elsas gratefully acknowledges financial support from the German Research Foundation DFG under the grant EL 256/1-1. 


\section{Introduction}

The vices and virtues of bank debt financing seem nowadays rather well understood. The existence of a bank lender, who is able to renegotiate debt contracts and acquires private information appears to be optimal in particular for informationally opaque borrowers: Close ties between a bank and its debtor provide incentives for information production and monitoring, enable (efficient) renegotiation of contracts, and allow for intertemporal transfers. This may constitute a financing arrangement otherwise not (or only more costly) available to firms. This concept is typically characterized as relationship lending (Mayer (1988), Sharpe (1990), Rajan (1992), Boot (2000)), and it is usually presumed to be based on exclusivity: the relationship lender is the only bank providing debt to the firm. The dark side of such a relationship is also well known: If the relationship bank can renegotiate contracts and the borrower is tied to the bank, this gives rise to a certain degree of monopoly power and therefore the potential ability of the bank to extract rents. If this hold-up problem is too severe, theory predicts the choice of a multitude of (equal) lenders, thereby reducing their bargaining power and avoiding the renegotiation of debt contracts (Dewatripont and Maskin (1995), von Thadden (1992)). ${ }^{1}$

However, empirical evidence suggests that this story is not able to explain an important feature of observed capital structures: Even those firms mostly in need of monitoring-intensive debt financing (young, small, and innovative firms) quite generally have a multitude of bank lenders. Thus, single bank financing is an exception rather than the rule (Ongena and Smith (2001), Detragiache, Garella, and Guiso (2000)). Does this suggest that relationship lending is a neat concept without consequences for the real world? Recent empirical evidence renders such a conclusion to be premature: As indicated by the results of Petersen and Rajan (1994), Elsas and Krahnen (1998)) and others, multiple bank financing can coexist with the presence of one bank financier which is special. Hence, another type of relationship lending seems to exist, which can be characterized as multiple but asymmetric bank financing, where a pivotal bank with an informational privilege

\footnotetext{
${ }^{1}$ von Thadden (1995) shows that using long-term debt contracts with specific features can circumvent the hold-up problem without the need for multiple bank relationships.
} 
and bargaining power exists jointly with less informed "arm's-length" banks.

Unfortunately, economic theory does not have to say a lot why relationship lending may be an optimal debt financing instrument in the context of multiple bank financing. The objective of this paper is to make a first step towards filling this theoretical void. We develop a simple framework where multiple but asymmetric bank financing may arise as an optimal financing choice.

In our model, an entrepreneur seeks to finance an investment project which is ex ante profitable, but needs some investment in effort at an interim stage. The entrepreneur can choose between three financing structures: Single bank financing with bargaining power for this relationship bank, financing by a multitude of equal and individually small banks (arm's-length banks), or financing by a mixture of both, i.e. multiple but asymmetric banks. In the latter case, there exists one pivotal bank with a high financing share and bargaining power. These two characteristics, in combination with an informational advantage, reflect the archetype of a relationship lender, but in a situation of multiple bank financing.

The fundamental problem of financing results from uncertainty about the project's outcome, the banks right to withdraw funds at an interim stage, and the complementarity of their decisions. Every bank receives a signal about the project's quality which is used to decide on continuation of financing. A bank's decision then must take into account its respective signal, but decisions of other banks as well. This leads to strategic uncertainty and the risk of coordination failure, because there exist some values of the project's outcome where a firm may fail its obligations only because too many lenders withdraw at the interim stage.

Intuitively, such coordination risk increases in the number of creditors. The existence of a pivotal bank with bargaining power is one means to reduce such coordination risk. Small banks will tend to orientate their decisions not only on the strategic interaction with other small banks but on the expected behavior of the pivotal bank as well. ${ }^{2}$ Moreover, renegotiation of debt by the relationship

\footnotetext{
${ }^{2}$ Pagratis (2002) analyzes the role of banks in facilitating public debt exchange offers when asymmetric creditors face coordination problems. In resolving financial distress of the firm, he shows that the large creditor's actions allow small creditors to coordinate better. However, in contrast to our work the existence of a large lender and many small creditors is just assumed.
} 
lender can be beneficial because in bad states of the world, the relationship lender might be willing to forgive debt. In turn, however, a sole relationship lender is not necessarily optimal due to the hold-up problem. Simultaneously maintaining financing relationships with small banks may restrict the relationship lender's ability to extract rents in good states of the world. Hence, in general, the optimal financing structure is determined by balancing the risk of coordination failure and the hold-up-problem.

Our main contributions are as follows. First, we show that under some conditions the co-existence of arm's-length and relationship financing can endogenously be the optimal financing choice of firms. A multiple but asymmetric financing structure can be optimal for two reasons: i) The joint financing from small banks and one relationship lender balances the relationship lender's bargaining power and debt forgiveness, even without coordination risk regarding the small banks' withdrawal decisions. ii) When small banks' decisions are subject to the risk of coordination failure, financing from a relationship lender becomes more beneficial (ceteris paribus). An asymmetric financing structure is especially beneficial for risky firms or for firms with low expected cash-flow.

Second, instead of pointing to the relevance of the number of bank lenders as the key issue in multiple lending, we show that asymmetry in the relative importance (i.e. the financing shares) of banks in lending might also be essential. We thus complement the literature on multiple bank lending by analyzing lender concentration.

Finally, we show that the association between the importance of the relationship lender and the liquidation value of assets is non-monotonic. This helps to explain the ambiguity in empirical findings with respect to relationship lending and loan collateralization.

Of course, previous literature provides theoretical arguments for the benefits of multiple bank lending. First, multiple bank financing leads to a more strict budget constraint for the borrower. This explanation is the focus of Dewatripont and Maskin (1995) and Bolton and Scharfstein (1996). In the latter model, a larger number of financing banks complicates debt renegotiation in case of default. This reduces borrower incentives for strategic default, but decreases firm value in case of true liquidity default. The optimal capital structure balances both 
effects. ${ }^{3}$ Second, multiple lenders can be beneficial because diversification reduces the likelihood that borrower financing is terminated due to liquidity shocks to the lenders, see Detragiache, Garella, and Guiso (2000). Third, Carletti (2004) analyzes multiple banking if banks endogenously determine their degree of borrower monitoring, but monitoring represents a public good and exhibits economies of scale. The optimal lending structure then balances monitoring benefits (i.e. better project quality) against the cost of duplicated effort. Fourth, multiple bank lending may be used to reduce bargaining power of lenders to weaken the hold-up problem, as in von Thadden (1992) and just recently Hubert and Schäfer (2002). Our model is mostly related to this type of explanation.

A salient feature of all of the aforementioned models is that lenders generally are presumed to have equal shares in borrower financing. Complementing these papers, our model analyzes the optimal concentration of debt financing from banks with and without the ability to renegotiate loan contracts.

Holmström and Tirole (1997) show that only a fraction of funds needs to be financed by a relationship lender to deter the borrower from moral hazard. The remaining funds can be raised from passive investors like the market or uninformed arm's-length banks. In contrast, in our model the small lenders have an active role in that they can withdraw financing at an interim stage. Hence, we complement Holmström and Tirole (1997) because our small investors truly resemble banks, which can actively make decisions that affect the borrower and the relationship lender.

The remainder of the paper is organized as follows. Section 2 describes the model's setup. We lay out the basic framework and characterize the financing problem of the borrower regarding its choice of debt structure. Further, we discuss the coordination problem of bank lenders. In Section 3 we derive the optimal financing structure. In Section 4, we examine comparative statics to derive empirical implications. In Section 5 we discuss an extension of our model, allowing for asymmetric information between lenders. Section 6 concludes.

\footnotetext{
${ }^{3}$ In a related model, Welch and Bris (2001) conjecture that a larger number of creditors increases the costs of enforcing lender claims in financial distress. This might be balanced against more efficient continuation decisions in financial distress by more concentrated lenders, but this is not explicitly modelled.
} 


\section{Relationship Lending with Multiple Banks and Asymmetry: A Stylized Model}

\subsection{Basic Framework}

The objective of our model is to explore conditions where multiple but asymmetric bank lending occurs as an optimal capital structure choice of a firm. We consider two types of bank financing: a relationship bank ("large lender" for simplicity) and arm's-length banks ("small lenders"). A relationship bank may renegotiate loans, thereby earning positive ex post rents in good states of the world, or forgive debt in bad states of the world. Small "arm's-length" bank lenders, in turn, cannot renegotiate loan contract terms. However, all lenders resemble banks in that they can withdraw financing at an interim stage.

Small lenders each have an equal and small share in the total small lender financing. As is standard, we assume for simplicity that the number of small lenders approaches infinity. This simplifies the analysis without making any difference regarding the strategic behavior of small lenders (see e.g. Morris and Shin (2001) and Hubert and Schäfer (2002)).

We incorporate these features in an extension of the model by Hubert and Schäfer (2002). The timing is as follows (the timeline is also depicted in Figure 1):

0. The firm tries to raise debt to finance an investment project with uncertain cash flows $\theta$. The firm decides on the size of the large lender, $\lambda \in[0,1]$. It offers a contractual debt repayment $D$.

1. Creditors decide whether or not to borrow to the firm. This leads to participation constraints in the choice of $\lambda, D$.

2. Information about cash flow $\theta$ becomes uncovered. In the standard model, we assume perfect information by all creditors (and the firm). Effects of imperfect and private signals are discussed as a model extension in Section 5 .

3. All lenders simultaneously decide whether to extend financing, or withdraw credit receiving an early liquidation value $K$. In addition, the large lender 
renegotiates the debt repayment and sets $D^{*}$. For reasons of simplicity, we assume that the large lender has full bargaining power and extracts all profits subject to outside options of the firm. Small lenders cannot renegotiate their debt contracts.

4. The firm decides on investing effort $V$ in the project. If it does, it has to refinance withdrawn debt.

5. Realization of cash flows and payments. If the firm did invest and refinance, the project is successful with cash flow $\theta$ and debt contracts are paid off. If the firm did not invest $V$, the project fails. The final liquidation value of the remaining assets is normalized to zero.

Figure 1: Timeline of the Model

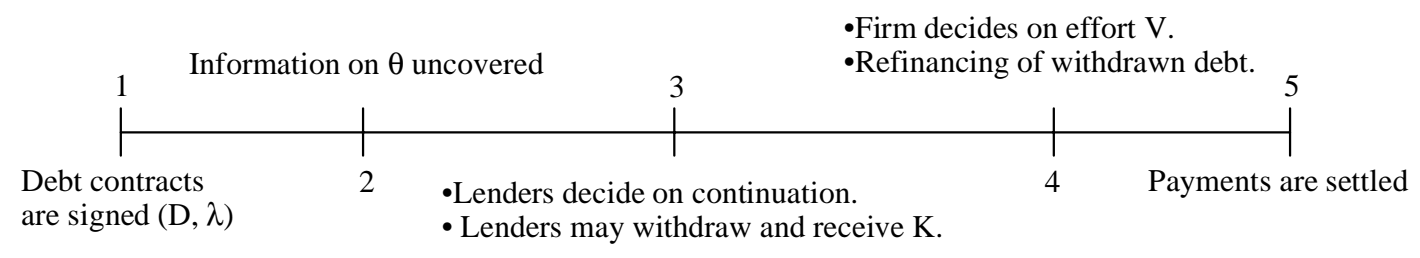

The interim (non-pecuniary and non-contractible) investment by the firm in $\mathrm{t}=4$ serves to establish an incentive problem, and one may think of the interim investment as effort to manage the project successfully. The initial investment is normalized to 1.

The project is characterized by the prior distribution of cash flow and by its liquidation value. If $V$ is invested and the project carried out until the end, the project generates cash flow $\theta$ in $\mathrm{t}=5$ which is uniformly distributed on the interval $[\mu-\tau, \mu+\tau] . \mu$ is the ex ante expected cash-flow of the project, to which we refer sometimes as project quality. The density of $\theta$ is given by

$$
f(\theta)=\left\{\begin{array}{cll}
\frac{1}{2 \tau} & \text { if } & \mu-\tau<\theta<\mu+\tau \\
0 & \text { else }
\end{array}\right.
$$

The variance is $\operatorname{Var}(\theta)=\frac{1}{3} \tau^{2}$. The uniform distribution is assumed for analytical tractability. However, the economic rationale behind our results is independent from the precise shape of the distribution of cash-flow. 
Lenders are allowed to decide on continuation of financing or withdrawal at the interim stage $t=3$. The firm can refinance if lenders withdraw. For small lenders the cost of refinancing are denoted by $W$ per unit of capital. For the large lender the cost of refinancing is $W^{*} \geq W$. Hence, the firm faces switching costs of changing lenders. This assumption serves for two purposes. First, it is a stylized way of establishing bargaining power for the large lender (but not for small ones). While the large lender can use his knowledge about $W^{*}$ and $\theta$ at the interim stage to renegotiate the loan contract, small lenders must stick to the ex ante agreed on loan contract terms. Second, the fact that the withdrawal of each lender increases financing costs establishes complementarity of lenders' strategies.

Lenders simultaneously decide on credit continuation. A lender who withdraws at the interim stage receives a liquidation value of $K$ per unit of capital. We assume that $K$ does not differ for large and small lenders. We provide a more detailed analysis of the role of such "collateral" in Section 4.

\subsection{Credit Extension}

In order to derive the optimal financing of the firm, it is useful to characterize some model features and provide some definitions up-front. In particular, we first discuss the interaction of the firm and its creditors, once the debt contract $(\lambda, D)$ is fixed.

The firm's decision

At $t=4$, the firm decides on spending effort $V$. If it does, it has to refinance withdrawn credit from stage 3 , where creditors decided on continuation or withdrawal. If it does not, the project fails. The firm's decision depends on $\theta$ and on the fraction of small lenders that terminated credit supply, denoted by $T$. Further, the firm must also refinance the large lender if he decided for withdrawal.

Suppose a fraction $T \in[0,1]$ of small lenders withdraws credit. Refinancing small lenders' credits costs $W$ per unit. Refinancing large lenders' credit costs $W^{*}$ per unit. We assume $D>K$, and $W^{*} \geq W>D$. In addition, we assume that $\mu-\tau<V+K$ and $\mu+\tau>V+W^{*}$, i.e. the support of $\theta$ is sufficiently 
large. This guarantees that in worst cases, cash flow is so low that it is inefficient to refinance the firm in stage 3. In best cases, however, cash flow is sufficient to cover costs of a single large lender and leave some profits to the firm. The firm's decision can now be characterized as follows.

If the large lender extends credit and the firm puts effort in stage 4, its payoff is

$$
\pi_{F}=\theta-V-\lambda D^{*}-(1-\lambda)(1-T) D-(1-\lambda) T W
$$

If the large lender withdraws, the firm refinances and puts effort in the project, its payoff is

$$
\pi_{F}=\theta-V-\lambda W^{*}-(1-\lambda)(1-T) D-(1-\lambda) T W
$$

Finally, if the firm puts no more effort in the project at stage 4, its payoff is zero, since all remaining assets are seized by the creditors. In the subgame starting at $\mathrm{t}=4$ the firm puts in effort, if net profits $\pi_{F}$ are non-negative. This constitutes an incentive constraint for the firm.

The firm's behavior at this stage depends on creditor decisions at $t=3$, i.e. the coordination of credit extension. Creditors decide on continuation or withdrawal of credits. They must take into account i) the strategies of the other lenders, ii) the firm's incentive to spend effort in $\mathrm{t}=4$, and iii) their information on $\theta$. The lenders' payoffs can be characterized as follows. A small lender gets $K$ if he withdraws. He gets $D$ if he extends and the firm is successful and 0 if the firm fails. The large lender gets $K$ if he withdraws. He gets $D^{*}$ if he extends and the firm is successful and zero if the firm fails.

For simplicity, we assume perfect information of all players. Decisions of lenders whether to extend or withdraw credits depend on $\theta$, which is uncovered at $t=2$, i.e. after debt contracts have been signed. In any equilibrium, the proportion of withdrawn credits is a function $T(\theta)$.

\section{The large lender's decision}

$D^{*}$ is determined by the renegotiation process between the firm and the large lender and also depends on $\theta$. If negotiations fail, the large lender can withdraw credit and gets $K$ per unit of capital. Ex post efficient negotiations succeed, 
whenever profitability $\theta$ is large enough to cover a repayment of at least $K$ to the large lender,

$$
\theta \geq V+\lambda K+(1-\lambda)[T(\theta) W+(1-T(\theta)) D] .
$$

One can distinguish two extreme cases from the point of view of the large lender. In the worst case, all small lenders withdraw credit, $T(\theta)=1$. This defines a failure point, $\bar{\theta}$, below which the project is terminated since $\theta$ is not sufficient to pay lenders and provide incentives for the firm to invest effort.

$$
\bar{\theta}=V+\lambda K+(1-\lambda) W .
$$

In the best case for the large lender, all small lenders extend credit, $T(\theta)=0$. This defines another critical failure point below which the project is terminated, labeled $\underline{\theta}$.

$$
\underline{\theta}=V+\lambda K+(1-\lambda) D .
$$

Both equations illustrate a crucial characteristic of multiple but asymmetric lending. Failure points are decreasing in the size of the large lender since $K<D$. This reflects the benefit of a large lender to forgive debt in bad states of the world.

For $\theta<\underline{\theta}$, we get a unique equilibrium with all creditors withdrawing credit. For $\theta>\bar{\theta}$, there is a unique equilibrium with all creditors extending credit. In the intermediate region $[\underline{\theta}, \bar{\theta}]$, there are two equilibria for each element, one at which creditors extend credit and one where they all withdraw.

As is standard for coordination games, in this case we end up with multiple equilibria in this subgame. Credit extension is efficient, whenever $\theta>\underline{\theta}$ and this equilibrium Pareto-dominates the coexisting equilibrium of withdrawal. There is strategic uncertainty, though, and there is no reason to expect that lenders act according to Pareto-efficiency. Various refinement theories define different thresholds. ${ }^{4}$ To understand the impact of coordination risk on optimal financing, we focus the analysis on two extreme situations: efficient coordination and inefficient coordination, i.e. maximin strategies that are associated with the inefficient failure point $\bar{\theta}$. As will be discussed in Section 5, allowing for noisy and private signals leads to a unique equilibrium in between these two extremes.

\footnotetext{
${ }^{4}$ For a discussion of theoretical refinements and experimental evidence see Heinemann (2002).
} 


\subsubsection{Efficient Coordination of Small Lenders}

Assume first that credits are extended whenever this is efficient. In this situation, there is no coordination risk. Nevertheless, having small lenders is associated with benefits and opportunity costs for the firm. First, the large lender participates in better states of the world and extracts surplus from the firm, i.e. the hold-up problem. But on the other hand, he is willing to soften the budget constraint and continue debt provision in some lower states of the world. At the critical state $\underline{\theta}$, cash flow is just sufficient to cover the costs of paying face value of debt $D$ to all small lenders and an amount $K$ to the large lender. But, since the large lender has full bargaining power he extracts all profits up to the point, where switching the large creditor (at costs $W^{*}$ ) is an alternative for the firm. This happens at

$$
\hat{\theta}=V+\lambda W^{*}+(1-\lambda) D>\underline{\theta} .
$$

At this point, cash flow is sufficient to pay face value to small creditors and to refinance the large credit. Note that $\hat{\theta}$ is increasing in the size of the large lender.

For $\theta<\underline{\theta}$, the firm is liquidated, for $\underline{\theta}<\theta<\hat{\theta}$, the firm is continued, but all profits are extracted by the large lender, and only for $\theta>\hat{\theta}$, the firm earns the cash flow exceeding $\hat{\theta}$.

For $\theta$ being uniformly distributed in $[\mu-\tau, \mu+\tau]$, expected profits of the firm are given by

$$
\begin{aligned}
\mathrm{E}\left(\pi_{F}\right) & =\frac{1}{2 \tau} \int_{\hat{\theta}}^{\mu+\tau}[\theta-\hat{\theta}] \mathrm{d} \theta=\frac{1}{4 \tau}[\mu+\tau-\hat{\theta}]^{2} \\
& =\frac{1}{4 \tau}\left[\mu+\tau-V-W^{*}+(1-\lambda)\left(W^{*}-D\right)\right]^{2} .
\end{aligned}
$$

From (6) one can see that expected profits are decreasing in the size of the large lender $\lambda$. $\hat{\theta}$ is increasing in $\lambda$, thus $\lambda$ reduces the set of states, in which the firm earns positive profits. Furthermore, in all of these states profits are decreasing with rising $\lambda$, that is, in the smaller interval profits will also be lower. The large lender is helpful in continuing the project in states where continuation is efficient (cash flows of the project are higher than the liquidation value), but he reaps all the benefits. Accordingly, conditional on $D$ being fixed (and ignoring participation constraints of lenders), a firm cannot benefit from having large lender in the case of efficient coordination. However, as we will see in Section 3 
below, an optimal debt structure takes participation constraints into account and determines $D$ endogenously. Since the large lender bears risk for the small lenders due to his debt forgiveness in bad states, asymmetric financing can nevertheless be the firm's best choice.

\subsubsection{Inefficient Coordination of Small Lenders}

As an alternative, let us now consider that small lenders coordinate on the most inefficient equilibrium and withdraw credits for all states $\theta<\bar{\theta}$. This introduces the maximum coordination risk and forces the firm to refinance withdrawn funds at costs $W$ per unit capital to continue the project.

At state $\bar{\theta}$, cash flow is just sufficient to refinance small lenders' credits and to pay an amount $K$ to the large lender. $\bar{\theta}$ is the threshold to failure. The threshold above which the firm earns positive profits is $\hat{\theta}$, provided that this exceeds $\bar{\theta}$. From the definitions of these terms, we find that

$$
\hat{\theta} \leq \bar{\theta} \quad \Leftrightarrow \quad \lambda \leq \hat{\lambda}=\frac{W-D}{W-D+W^{*}-K} .
$$

Note that $\hat{\lambda}<1$. If the large lender is sufficiently small, i.e. for $\lambda<\hat{\lambda}$, he can never extract all profits from the firm. In all states in which the project is continued, its cash flow exceeds the costs of replacing the large lender. In lower states, $\theta<\bar{\theta}$, cash flow does not suffice to replace small lenders, even when the large lender requires only $K$.

Expected profits of the firm are now given by

$$
E\left(\pi_{F}\right)=\frac{1}{2 \tau} \int_{\max \{\hat{\theta}, \bar{\theta}\}}^{\mu+\tau}(\theta-\hat{\theta}) \mathrm{d} \theta .
$$

With increasing $\lambda$, the two thresholds $\hat{\theta}$ and $\bar{\theta}$ move in opposite directions. If $\lambda>\hat{\lambda}$, any further increase reduces the set of states, in which the firm earns positive profits and it lowers these profits when they occur. Conditional on $D$ being fixed, the optimal size of the large lender is smaller than $\hat{\lambda}$ and balances marginal losses due to the hold-up problem with marginal gains from the positive effect that $\lambda$ has on the default point due to inefficient coordination of small lenders. When the size of the large credit is small, the coordination effect dominates the hold-up problem. 
To illustrate the role of $\lambda$, Figure 2 shows the profit of the firm $\left(\pi_{F}\right)$ in a situation where $\lambda<\hat{\lambda}$ or equivalently $\hat{\theta}<\bar{\theta}$. An increase in $\lambda$ shifts $\bar{\theta}_{1}$ to $\bar{\theta}_{2}$ and $\hat{\theta}_{1}$ to $\hat{\theta}_{2}$. If the firm is continued, bargaining power allows the large lender to extract some profits from the firm. The amount that can be extracted is increasing in $\lambda$. This lowers state-contingent profits of the firm. The effect of $\lambda$ on continuation of the project is positive, however. Raising $\lambda$ reduces the failure point $\bar{\theta}$ and increases the set of states in which the firm earns profits. The optimal size of the large lender balances the two effects.

Figure 2: Effects of Raising $\lambda$ on Critical States and Firm Profits

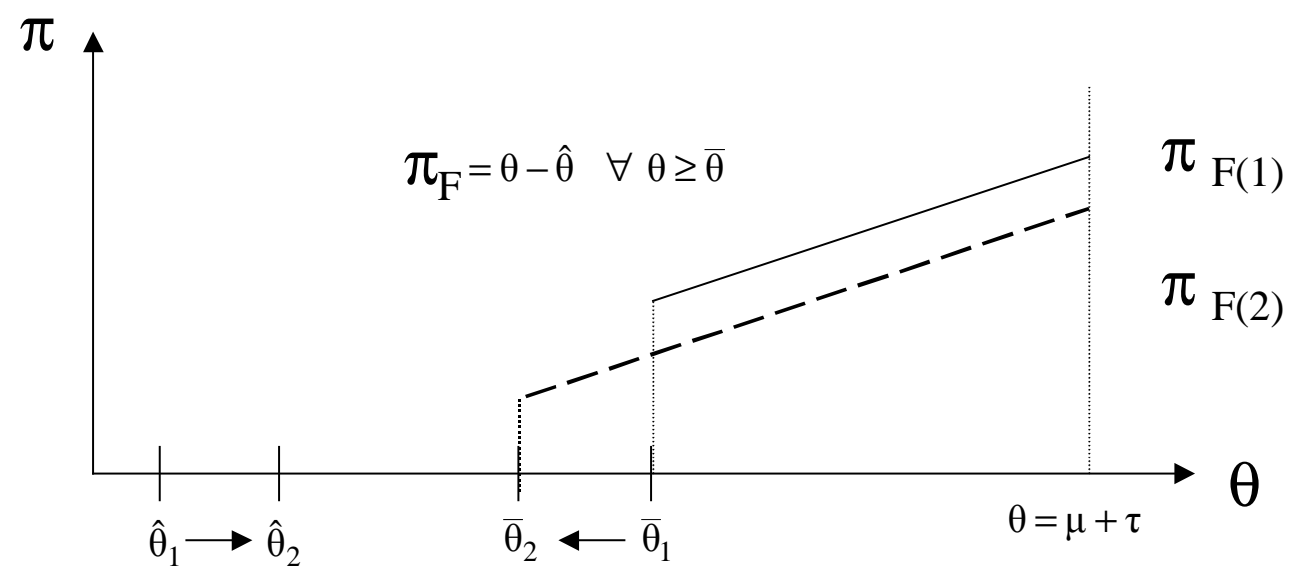

Using these insights, we can derive the optimal size of a relationship lender conditional on fixed $D$.

Theorem 1 Under inefficient coordination of small lenders and for given loan contracts with repayment $D$, the firm's profit maximizing financing structure is asymmetric, i.e. $0<\lambda^{*}<1$, if and only if $\mu+\tau<V+W+\frac{(W-K)(W-D)}{W^{*}-D}$. Then, the optimal size of the large lender is

$$
\lambda^{*}=\frac{(W-K)(W-D)-\left(W^{*}-D\right)[\mu+\tau-V-W]}{(W-K)\left[2 W^{*}+W-2 D-K\right]} .
$$

Otherwise, $\lambda^{*}=0$.

Proof: To derive the optimal size of the relationship bank, we maximize expected profits of the firm, using our knowledge that the optimal $\lambda$ will be lower 
than $\hat{\lambda}$. Then, expected profits are

$$
E\left(\pi_{F}\right)=\frac{1}{2 \tau} \int_{\hat{\theta}}^{\mu+\tau}(\theta-\hat{\theta}) \mathrm{d} \theta=\frac{1}{2 \tau}\left[\frac{(\mu+\tau)^{2}-\bar{\theta}^{2}}{2}-(\mu+\tau) \hat{\theta}+\hat{\theta} \bar{\theta}\right] .
$$

Using the definitions of $\hat{\theta}$ and $\bar{\theta}$, we get the derivative

$$
\frac{\partial E\left(\pi_{F}\right)}{\partial \lambda}=\frac{1}{2 \tau}\left[(W-K)(\hat{\theta}-\bar{\theta})-\left(W^{*}-D\right)(\mu+\tau-\bar{\theta})\right] .
$$

Setting the derivative equal to zero gives the profit maximizing $\lambda^{*}$, provided that it is non-negative. $\lambda^{*}$ depends on $\mu$ and $\tau$. Inserting $\hat{\theta}$ and $\bar{\theta}$ in (9) and solving $\frac{\partial E\left(\pi_{F}\right)}{\partial \lambda}=0$ for $\lambda$ gives

$$
\Leftrightarrow \quad \lambda^{*}=\frac{(W-K)(W-D)-\left(W^{*}-D\right)[\mu+\tau-V-W]}{(W-K)\left[2 W^{*}+W-2 D-K\right]}
$$

$\lambda^{*}$ is smaller than $\hat{\lambda}$. It is decreasing in $\mu+\tau$ and increasing in $V$.

$\lambda^{*}$ is positive, if and only if

$$
\mu+\tau<V+W+\frac{(W-K)(W-D)}{W^{*}-D}
$$

QED

This constitutes some first results in a situation with coordination risk: Having a large lender can be beneficial. $\lambda^{*}$, the optimal size of the large lender is decreasing in $\mu+\tau$. For sufficiently good projects or for a sufficient intermediate liquidation value $K$, financing does not require a large lender. The lower $\mu+\tau$, the larger is $\lambda^{*}$, but it remains below $\hat{\lambda}$ and is, thereby, always smaller than one.

\section{The Optimal Debt Structure}

The analysis in the preceding section treated the promised repayment of debt contracts, $D$, as an exogenous variable. Of course, this ignores lenders' participation constraints.

This aspect is of utmost importance, because the size of the large lender does not only affect firm's profits but lenders' profits as well. The larger the size of the relationship bank, the larger is the set of states, in which the project succeeds and small credits are payed off. Thereby, relationship lending increases 
expected payoffs of small lenders or, alternatively, reduces the risk premium that is included in the promised repayment $D$.

Optimal financing requires the firm to choose parameters $D$ and $\lambda$ in $\mathrm{t}=0$ that maximize expected profits, subject to the participation constraints of all lenders. In principle, there are four possible outcomes:

1. The project cannot be financed because no type of lender is willing to provide credit ex ante.

2. The project is financed only by small lenders $\left(\lambda^{*}=0\right)$.

3. The project is financed only by the large lender $\left(\lambda^{*}=1\right)$.

4. The project is financed asymmetrically by both the large and small lenders $\left(0<\lambda^{*}<1\right)$.

We are most interested in those cases, where multiple but asymmetric lending occurs as the optimal capital structure, i.e. the interior solution of case 4. Again, we proceed by distinguishing efficient and inefficient coordination of small lenders in the refinancing game.

\subsection{Optimal Debt Structure with Efficient Coordination}

With perfect information and efficient coordination, credits will be extended whenever $\theta \geq \underline{\theta}$.

Firm's expected profits

The firm earns $\theta-\hat{\theta}$ whenever that is positive. As shown in Section 2.2, expected profits, $\mathrm{E}\left(\pi_{F}\right)$, are given by (6):

$$
\mathrm{E}\left(\pi_{F}\right)=\frac{1}{2 \tau} \int_{\hat{\theta}}^{\mu+\tau}[\theta-\hat{\theta}] \mathrm{d} \theta=\frac{1}{4 \tau}\left[\mu+\tau-V-W^{*}+(1-\lambda)\left(W^{*}-D\right)\right]^{2} .
$$

The firm chooses $\lambda$ and $D$ such that expected profits are maximized. The firm's participation requires $\mathrm{E}\left(\pi_{F}\right) \geq 0$. Expected profits of the firm are decreasing in $\lambda$ and $D$. Iso-profit-curves are concave with slope $\frac{d \lambda}{d D}=\frac{-(1-\lambda)}{W^{*}-D}$.

$\underline{\text { Small Lenders' Participation }}$ 
Small lenders get $D$ if $\theta \geq \underline{\theta}$ and $K$ otherwise. Using the uniform distribution of $\theta$, small lenders' expected profits per unit of capital are

$$
\mathrm{E}\left(\pi_{S}\right)=K+(D-K) \operatorname{prob}(\theta>\underline{\theta})=K+(D-K) \frac{\mu+\tau-\underline{\theta}}{2 \tau} .
$$

Small lenders' participation requires $\mathrm{E}\left(\pi_{S}\right) \geq R$, where $R \geq 1$ represents the opportunity costs of capital. Since $\underline{\theta}$ is decreasing in $\lambda$, small lenders' expected profits are rising in the size of the relationship lender. Hence, participation of small lenders may require the existence of a relationship lender who takes a sufficiently large part of the debt. $\mathrm{E}\left(\pi_{S}\right) \geq R$ is equivalent to

$$
\lambda>\lambda_{S}=\frac{2 \tau(R-K)-(D-K)[\mu+\tau-V-D]}{(D-K)^{2}} .
$$

\section{Large Lender's Participation}

For $\lambda$ units of capital provided, the large lender gets $\lambda W^{*}$ whenever $\theta>\hat{\theta}$ (the region for which the firm makes profits), and $\lambda K$ if $\theta<\underline{\theta}$ (the firm is liquidated). Participation requires $\mathrm{E}\left(\pi_{L}\right) \geq \lambda R$. Thus, eliminating $\lambda$ yields payoffs per unit of capital.

In intermediate states $\underline{\theta}<\theta<\hat{\theta}$, the large lender extracts all profits out of the firm. Here, the payoff per unit of capital invested by the large lender is

$$
\pi_{L}=\frac{\theta-V-(1-\lambda) D}{\lambda} .
$$

Prior expected profits of the large lender are then equal to

$$
\begin{aligned}
\mathrm{E}\left(\pi_{L}\right) & =K \operatorname{prob}(\theta<\underline{\theta})+\int_{\underline{\theta}}^{\hat{\theta}} \frac{\theta-V-(1-\lambda) D}{2 \tau \lambda} \mathrm{d} \theta+W^{*} \operatorname{prob}(\theta>\hat{\theta}) \\
& =K+\frac{\mu+\tau-V-(1-\lambda) D-\lambda \frac{W^{*}+K}{2}}{2 \tau} .
\end{aligned}
$$

The large lender's participation requires $\mathrm{E}\left(\pi_{L}\right) \geq R$, which is equivalent to

$$
\lambda \leq \lambda_{L}=\frac{\mu+\tau-V-D-\frac{2 \tau(R-K)}{W^{*}-K}}{\frac{W^{*}+K}{2}-D} \quad \text { if } D<\frac{W^{*}+K}{2}
$$

and

$$
\lambda \geq \lambda_{L} \quad \text { if } D>\frac{W^{*}+K}{2} .
$$


The term $\frac{W^{*}+K}{2}$ represents the average payoff per unit of capital that the large lender receives in intermediate states $\underline{\theta}<\theta<\hat{\theta}$. Increasing $\lambda$ extends the set of intermediate states by raising $\hat{\theta}$ and reducing $\underline{\theta}$. If $D<\frac{W^{*}+K}{2}$, an increase of $\lambda$ has a larger effect on $\hat{\theta}$ than on $\underline{\theta}$. This reduces the expected payoff for the large lender. If $D>\frac{W^{*}+K}{2}$, an increase of $\lambda$ has the opposite effect.

Optimal debt contract

Combining the participation constraints of both types of lenders defines the set of contracts $(\lambda, D)$ from which the firm can choose. Expected profits of the firm are given by (6). They are decreasing in $\lambda$ and $D$. Iso-profit-curves are concave with slope $\frac{d \lambda}{d D}=\frac{-(1-\lambda)}{W^{*}-D}$.

Maximizing expected profits of the firm with respect to the lenders' participation constraints requires to consider several distinct cases. The optimal financing structure depends on the difference $R-K$ and on other exogenous parameters. The precise solution is analyzed in Appendix A. Here, we only give the general results.

Theorem 2 a) The firm can be financed if and only if

$$
R-K<\frac{W^{*}-K}{2 \tau}\left[\mu+\tau-V-\frac{W^{*}+K}{2}\right] \equiv L^{C} .
$$

b) The firm is financed by a single large lender $(\lambda=1)$, if and only if

$$
L_{1} \equiv \frac{W-K}{2 \tau}(\mu+\tau-V-K) \leq R-K \leq L^{C} .
$$

This case requires $W^{*}-W$ and $\mu+V$ to be sufficiently large.

c) For each combination of $\mu, \tau, V, K, W, W^{*}$ that fulfills the basic assumptions of our model, there is an interval $[\underline{L}, \bar{L}]$ with non-empty interior, such that for $\underline{L}<R-K<\bar{L}$ the optimal financing structure is asymmetric, i.e. $0<\lambda<1$. Note that $\bar{L}=\min \left\{L_{1}, L^{C}\right\}$.

d) For sufficiently low $R-K$, the firm is financed by small lenders only $(\lambda=0)$.

e) The critical values of $R-K$ at which the financing structure changes $\left(L^{C}\right.$, $\left.L_{1}, \bar{L}, \underline{L}\right)$, are monotonically increasing in $\mu$ and decreasing in $V$. 
The proof is given in Appendix A. Note that the expression $R-K$ can be interpreted as loss given default from the banks' perspective and, therefore, represents one dimension of credit risk. Also it reflects the specificity of firm assets, with lower liquidation values at the interim stage the more specific the assets.

Figure 3: Optimal Financing Structure under Efficient Coordination

The figure illustrates Theorem 2 and shows feasible regions of the optimal financing structure, $\lambda^{*}$, with efficient coordination of small lenders. Fixed parameters equal $K=0.8, W=1.4, W^{*}=1.6, V=0.4$, and $\tau=1$.

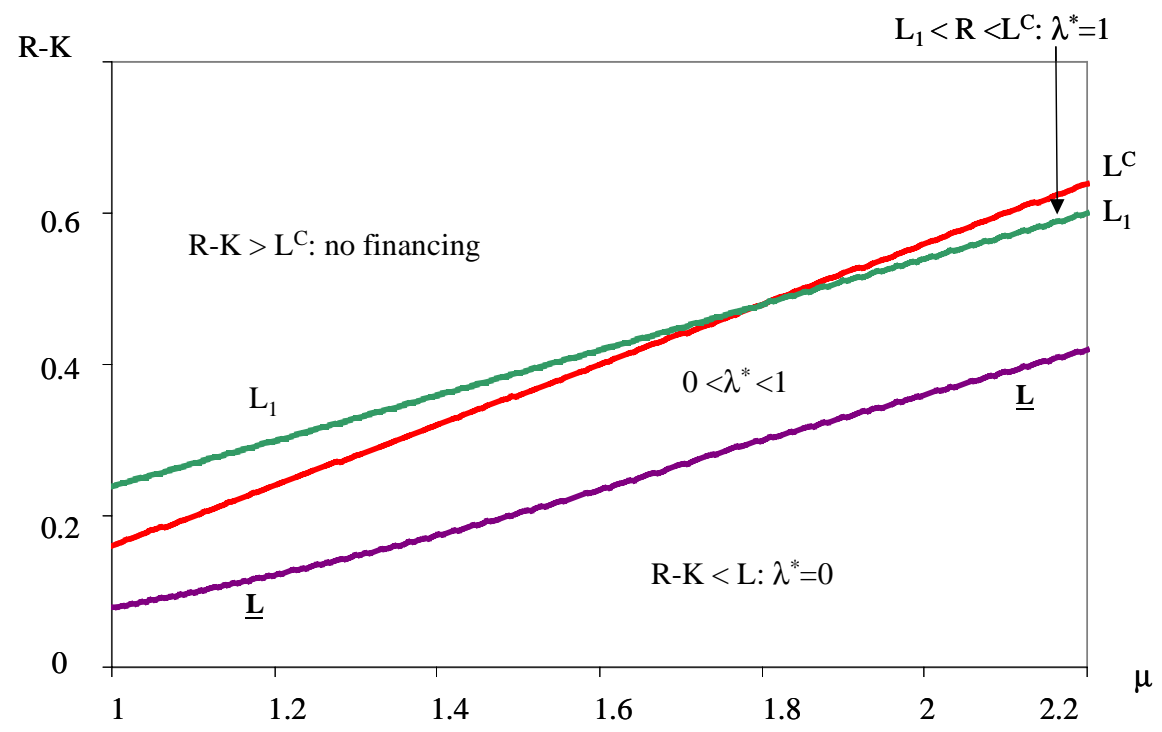

Figure 3 illustrates Theorem 2 using a generic combination of parameters and showing the implied optimal financing structures. For any combination of $W^{*}$, $W, K, \mu, \tau$ and $V$ we find that (i) the firm cannot be financed if $R-K$ is sufficiently large (with the critical boundary $L^{C}$ ), (ii) there is some $R-K$ below which the firm is financed by small lenders only (with the critical boundary $\underline{L}$ ), and (iii) there is an intermediate range for $R-K$, in which the optimal financing structure is asymmetric $([\underline{L}, \bar{L}])$. In the upper right corner of the figure, one can see that pure relationship financing, $\lambda=1$, occurs only for the specific situation where parameters are such that $L_{1} \leq R-K \leq L^{C}$. We would like to emphasize that for $R-K=L^{C}<L_{1}$ the firm will choose an asymmetric financing structure, i.e. $\lambda$ is bound below 1 , even when the firm is on the edge of being financed.

Figure 4 depicts a typical situation of an interior solution for a project of 
lower quality and intermediate opportunity costs, and plots the participation constraints of the large lender $\left(\lambda_{L}(D)\right)$, small lenders $\left(\lambda_{S}(D)\right)$, and firm's isoprofit curves. The optimal capital structure is denoted by $\left(D^{* *}, \lambda^{* *}\right)$.

Figure 4: Optimal Capital Structure with Efficient Coordination

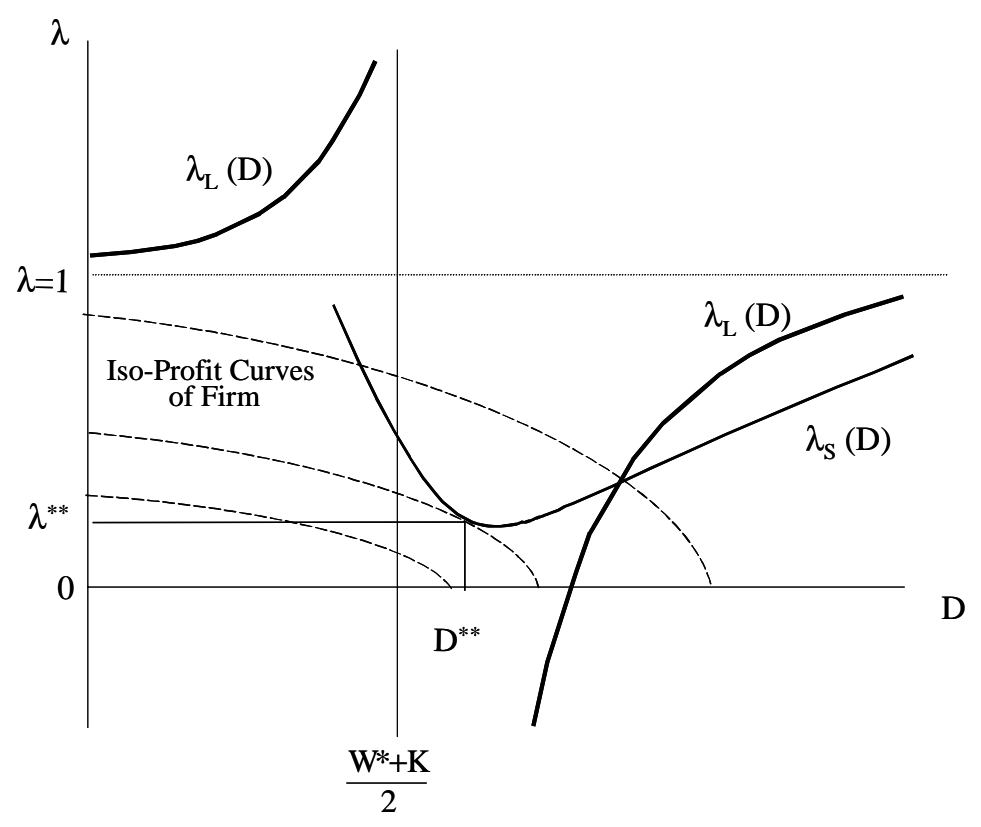

How is it possible that the existence of a large lender is beneficial for the firm, although we learned in Section 2.2 that at the interim stage the existence of a large lender is always detrimental to firm profits? The difference in the ex ante perception comes from the fact that the large lender is able to renegotiate his debt contract, thereby allowing the continuation of the firm in more states of the world. The debt repayment $D$ that is promised to small lenders in $t=0$ includes a risk premium to compensate lenders for the default risk of the firm $(K<D)$. If the presence of the large lender extends the states of nature where the firm is continued, this reduces the default risk ex ante and, thereby, the repayment that must be promised to small lenders.

As Figure 3 shows, the borders between different financing structures are increasing functions in a $\mu-(R-K)$-space. That is, for low opportunity costs of capital or high expected cash flow, a firm is more likely to choose financing with a 
low share of debt concentrated on a single lender or without relationship lender. Simulations indicate that there are monotone relationships and $\lambda$ is decreasing with decreasing $R$ and rising $\mu$.

\subsection{Optimal Debt Structure with Inefficient Coordination}

For the case of inefficient coordination, we have already shown that asymmetric financing with $0<\lambda<1$ may be the optimal choice, when $D$ is exogenous and sufficiently low. Now, we also take participation constraints into account. Credits will be extended whenever

$$
\theta \geq \bar{\theta}=V+\lambda K+(1-\lambda) W=V+W-\lambda(W-K)
$$

Here, the failure point does not depend on $D$.

Firm's Expected Profits

If credits are extended, the firm earns positive profits if and only if $\theta \geq \hat{\theta}$. As shown in section $2.2, \bar{\theta}<\hat{\theta}$ is equivalent to $\lambda>\hat{\lambda}$. $\hat{\lambda}$ is a decreasing and concave function of $D$ with $\hat{\lambda}(D=W)=0$.

Firm's expected profits are

$$
\mathrm{E}\left(\pi_{F}\right)=\frac{1}{2 \tau} \int_{\max \{\bar{\theta}, \hat{\theta}\}}^{\mu+\tau}(\theta-\hat{\theta}) \mathrm{d} \theta= \begin{cases}\frac{(\mu+\tau-\hat{\theta})^{2}}{4 \tau} & \text { if } \quad \lambda>\hat{\lambda} \\ \frac{(\mu+\tau)^{2}-\bar{\theta}^{2}-2 \hat{\theta}(\mu+\tau-\bar{\theta})}{4 \tau} & \text { if } \quad \lambda<\hat{\lambda}\end{cases}
$$

For $\lambda>\hat{\lambda}$, we find $\mathrm{E}\left(\pi_{F}\right)$ decreasing in $\lambda$ and $D$ with iso-profit-curves decreasing and concave with slope $\frac{-(1-\lambda)}{W^{*}-D}$, as in the case of efficient coordination.

For $\lambda=\hat{\lambda}$, expected profits are also decreasing in $D$.

For $\lambda^{*}<\lambda<\hat{\lambda}$, iso-profit curves are decreasing and concave. For $\lambda<\lambda^{*}$, iso-profit curves are increasing and convex (see Figure 5 for an example).

\section{Small Lenders' Participation}

The payoff to a small lender is $K$ if $\theta<\bar{\theta}$ and $D$ otherwise. The small lenders expected profits are

$$
\mathrm{E}\left(\pi_{S}\right)=K+(D-K) \operatorname{prob}(\theta>\bar{\theta})=K+(D-K) \frac{\mu+\tau-\bar{\theta}}{2 \tau} .
$$


This is similar to the case with efficient coordination except for the critical threshold $(\bar{\theta}$ instead of $\underline{\theta})$, which reflects the change in our assumption regarding small lender coordination.

Participation of the small lender requires

$$
\mathrm{E}\left(\pi_{S}\right) \geq R \quad \Leftrightarrow \quad \lambda \geq \lambda_{S}^{I C}=\frac{2 \tau \frac{R-K}{D-K}+V+W-\mu-\tau}{W-K}
$$

The superscript IC denotes the case of inefficient coordination of small lenders. $\lambda_{S}^{I C}$ is a decreasing and convex function in $D$ and increasing in $R$.

Furthermore,

$$
\begin{aligned}
& \lambda_{S}^{I C}(D)<1 \quad \Leftrightarrow \quad D>D_{1}=K+\frac{2 \tau(R-K)}{\mu+\tau-V-K} . \\
& \lambda_{S}^{I C}(D)>0 \quad \Leftrightarrow \quad D<D_{0}=K+\frac{2 \tau(R-K)}{\mu+\tau-V-W}, \quad D_{0}>D_{1}
\end{aligned}
$$

A typical example of the small lender's participation constraint is given in Figure 5.

\section{Large Lender's Participation}

The large lender's payoff is

$$
\pi_{L}= \begin{cases}K & \text { if } \theta<\bar{\theta} \\ \frac{\theta-V-(1-\lambda) D}{\lambda} & \text { if } \quad \bar{\theta} \leq \theta<\hat{\theta} \\ W^{*} & \text { if } \theta \geq \bar{\theta} \wedge \theta \geq \hat{\theta}\end{cases}
$$

Expected payoff to a large lender is

$$
\mathrm{E}\left(\pi_{L}\right)= \begin{cases}K \operatorname{prob}(\theta<\bar{\theta})+W^{*} \operatorname{prob}(\theta \geq \bar{\theta}) & \text { if } \quad \lambda \leq \hat{\lambda} \\ K \operatorname{prob}(\theta<\bar{\theta})+\int_{\bar{\theta}}^{\frac{\theta}{\theta-V-(1-\lambda) D}} \frac{\theta}{2 \tau \lambda} \mathrm{d} \theta+W^{*} \operatorname{prob}(\theta \geq \hat{\theta}) & \text { if } \quad \lambda \geq \hat{\lambda}\end{cases}
$$

Participation requires $\mathrm{E}\left(\pi_{L}\right) \geq R$, which leads to the participation constraint

$$
\mathrm{E}\left(\pi_{L}\right)= \begin{cases}\frac{K\left(\bar{\theta}-\lambda W^{*}-\mu+\tau\right)-W^{*}(V+(1-\lambda) W-\mu-\tau)}{2 \tau} \geq R & \text { if } \quad \lambda \leq \hat{\lambda} \\ \frac{(V+(1-\lambda) D) \bar{\theta}-\frac{1}{2} \bar{\theta}^{2}-(V+(1-\lambda) D) \hat{\theta}+\frac{1}{2} \hat{\theta}^{2}}{2 \lambda \tau}+\frac{K(\bar{\theta}-\mu+\tau)}{2 \tau}+\frac{W^{*}(\mu+\tau-\hat{\theta})}{2 \tau} \geq R & \text { if } \quad \lambda>\hat{\lambda}\end{cases}
$$

Let us concentrate on the case $\lambda \leq \hat{\lambda}$. Solving for $\lambda$ yields the space of feasible financing shares meeting the large lender's participation constraint

$$
\lambda>\lambda_{L}^{I C}=\frac{2 \tau \frac{R-K}{W^{*}-K}-\mu-\tau+V+W}{W-K},
$$


which is independent from $D$. For $\lambda \leq \hat{\lambda}$, the payoff to the large lender is $K$ in case of failure and $W^{*}$ in case of success. The failure point $\bar{\theta}$ does not depend on $D$ either, because we assumed most inefficient coordination of small lenders. Here, the size of the large lender is the only determinant of the failure point (provided that $\lambda<\hat{\lambda}$ ). Participation requires this size to be sufficiently large to increase the probability of success to a level at which large lender's expected payoff exceeds opportunity costs $R$.

For $\lambda \leq \hat{\lambda}$ the large lender's constraint is smaller than $\lambda_{S}^{I C}$ for all $D<W^{*}$.

Theorem 3 For inefficient coordination of small lenders in the refinancing game, the optimal financing structure $\left(D^{* * *}, \lambda^{* * *}\right)$ is such that $\lambda^{* * *}>\lambda^{*}(D)$, whenever the firm can be financed at all.

Proof: If the firm can be financed, the optimal $\left(D^{* * *}, \lambda^{* * *}\right)$ is either such that $\lambda^{* * *}>\hat{\lambda}(D)>\lambda^{*}(D)$, or $\lambda^{* * *}<\hat{\lambda}(D)$. In the latter case $\lambda_{S}^{I C}>\lambda_{L}^{I C}$, so that the large lender's constraint is not binding. The small lenders' constraint has a negative slope, while iso-profit curves have negative slope only for $\lambda>\lambda^{*}$. Hence, the optimal financial structure does always imply $\lambda^{* * *}>\lambda^{*}(D)$.

QED

The theorem shows that debt forgiveness of the large lender is valuable for small lenders. Compared to the situation where $D$ is given exogenously (with the profit maximizing $\lambda^{*}$, see Section 2.2), taking small lenders' participation constraint into account tends to raise the optimal size of the large lender.

In the case of efficient coordination we saw that the firm will always pick $\lambda=0$ if the loss given default is sufficiently low. This does not apply to the case of inefficient coordination.

Theorem 4 If $R-K$ is sufficiently small and $\mu<V-\tau+W+\frac{(W-K)^{2}}{W^{*}-K}$, then $\lambda>0$.

Proof:

$$
R-K \rightarrow 0 \Rightarrow \lambda_{S}(D) \rightarrow \frac{V+W-\mu-\tau}{W-K}<0 .
$$

Thus, for sufficiently low $R-K$, small lenders' participation constraint is not binding and the optimal contract $\left(D^{* * *}, \lambda^{* * *}\right)$ approaches $\left(K, \lambda^{*}(D=K)\right)$, provided that

$$
\lambda^{*}(D=K)>0 \quad \Leftrightarrow \quad \mu<V-\tau+W+\frac{(W-K)^{2}}{W^{*}-K} .
$$


Theorem 4 tells us that for some projects asymmetric financing is optimal, even when the loss given default is small. The reason is that inefficient coordination of lenders in cases of financial distress reduces prior expected returns in the absence of a relationship bank.

Figure 5 shows an example for the case of an optimal $\lambda$ between zero and one, where $\lambda_{S}^{I C}$ and $\lambda_{L}^{I C}$ denote the participation constraints of small lenders and the large lender, respectively, $\pi_{F}=c_{1,2}$ denotes iso-profit curves of the firm with $c_{1}<c_{2}$, and $\left(\lambda^{* * *}, D^{* * *}\right)$ denotes the optimal debt contract.

Figure 5: Optimal Capital Structure with Inefficient coordination

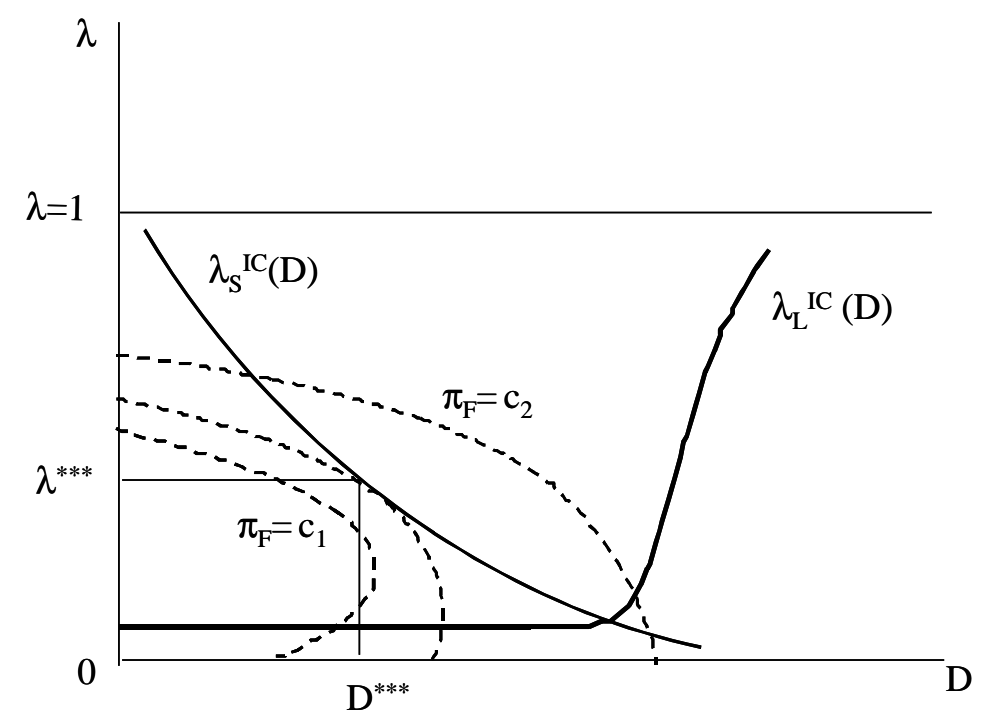

\section{The Role of Collateral}

Several empirical studies on relationship lending analyze the association between the incidence of relationship lending and collateralization of loan contracts. The results are mixed, however. While some studies find that relationship lenders are on average more collateralized than arm's-length lenders (see Elsas and Krahnen (2002), Degryse and van Cayseele (2000)), others find the opposite (see Berger and Udell (1995), Harhoff and Körting (1998)). Our model can help explaining 
this seemingly contradictory pattern, because i) all of these studies analyze a cross-section of firms with financing from multiple banks, and ii) relationship lending is often identified by the share of the relationship lender of total borrower financing (or correlated measures). ${ }^{5}$

In our model, the early liquidation value $K$ serves as collateral for lenders. For instance, one may think of a situation where the firm raises capital ex ante to finance certain input factors in the production process. These assets are saleable at the interim stage $t=3$ for $K$ and can be offered as collateral. Therefore, higher asset specificity translates into a lower collateral value $K$. Now, if (a fraction of the) lenders decide to withdraw credit at $t=3$, they receive assets and sell them. A firm who nevertheless wants to continue the project refinances the withdrawn credit, replacing the input factors with the money taken up.

We assume that the liquidation value does not differ per se for relationship and arm's-length lenders, and that no priority structure of collateralization exists. Hence, each financier's share of $K$ is proportional to its share of borrower financing. The early liquidation value characterizes a project together with distributional parameters, so that it differs in the cross-section of firms.

The association between collateral and the optimal financing share is nontrivial. Collateral affects renegotiations between the firm and the large lender. Higher collateral reduces the loss given default and thereby relaxes lenders' participation constraints. However, it also reduces the maximum debt forgiveness by the large lender and, thereby, raises the prior probability of default. This has ambiguous implications for the optimal size of the large lender, especially in the case of inefficient coordination.

To explain this relationship, let us focus on the case of inefficient coordination. For exogenously given face value of debt $D$, the firm chooses a relationship lender of size $\lambda^{*}$ provided that $\lambda^{*} \geq 0$.

Theorem 5 With rising $K, \lambda^{*}$ is first decreasing and then increasing.

Proof: Consider expected profits of the firm as a function of $\lambda . \lambda^{*}$ is defined by $\frac{\partial E\left(\pi_{F}\right)}{\partial \lambda}=0$. Equation (9) implies that the cross derivative of this expression

${ }^{5}$ See Elsas (2004) for an analysis of proxy variables to identify relationship lending in empirical work. 
with respect to $K$ is

$$
\frac{\partial^{2} E\left(\pi_{F}\right)}{\partial \lambda \partial K}=\frac{1}{2 \tau}[W-D-2 \lambda(W-K)] .
$$

If this is negative at some $\lambda$, then a rise in $K$ lowers the slope of expected profits at the respective $\lambda$. Evaluating this cross derivative at $\lambda^{*}$ we can conclude whether $K$ raises or lowers $\lambda^{*}$.

$$
\frac{1}{2 \tau}\left[W-D-2 \lambda^{*}(W-K)\right]<0 \quad \Leftrightarrow \quad K<W-2 \frac{W^{*}-D}{W-D}[\mu+\tau-V-D] .
$$

Thus, for low $K$ the slope of expected profits at the previously optimal $\lambda$ becomes negative, which implies that $\lambda^{*}$ must be reduced. If $K$ exceeds a critical level, a further increase in $K$ raises the optimal size of the large lender. $\quad$ QED

The economic rationale of this result can be understood if we compare the two effects of relationship lending that are balanced by $\lambda^{*}$. An increase in $\lambda$ reduces the failure point and thereby increases the set of states in which the firm earns positive profits, but it reduces profits of the firm in these states of nature. An increase in $K$ raises the failure point, but has no effect on state contingent profits $\theta-\hat{\theta}$.

We know that $\partial \bar{\theta} / \partial \lambda=-(W-K)$. The effect of $\lambda$ on the default point is stronger, the smaller $K$ is. For low collateral $K$ the firm attributes more weight to the positive effect that relationship lending has on the default point and chooses a higher $\lambda$. The relationship is not monotone, though, because an increase in $K$ reduces the number of states in which the firm earns positive profits. Thereby, an increase in $K$ also weakens the negative effect that relationship lending has due to the hold-up problem. If $K$ becomes large, the latter effect may dominate, and any further increase in $K$ may lead to a rise in $\lambda$.

A positive effect of $K$ on $\lambda$ requires that $\mu+\tau-V, W$, and/or $W^{*}$ are small in comparison with $D$. Only then, the effect of $K$ on the left margin of the set of states in which the firm succeeds is severe enough to make an increase in $\lambda$ profitable ex ante.

When repayments are treated as endogenous, a higher liquidation value affects the optimal financing structure also because it reduces the losses that withdrawing lenders incur at the refinancing stage. This increases expected payoffs and relaxes participation constraints of all lenders. Whenever, participation constraints are 
binding, they require a minimum size of the large lender. Hence, any relaxation of these constraints strengthens the case for a negative impact of collateral on the optimal size of the large lender.

In sum, a non-linear association between $K$ and the optimal financing share is to be expected. Deriving the partial derivative for the optimal financing share is analytically intractable and we rely on simulations. Figure 6 plots the optimal financing share for different values of $K$ in the case of inefficient coordination. For the other parameters, we have chosen $\mu=1.8, \tau=0.9, V=0.4, R=1$, $W^{*}=1.3$, and $\left.W=1.25\right)$.

Figure 6: The Optimal Financing Share of Relationship Lending with Varying Liquidation Values

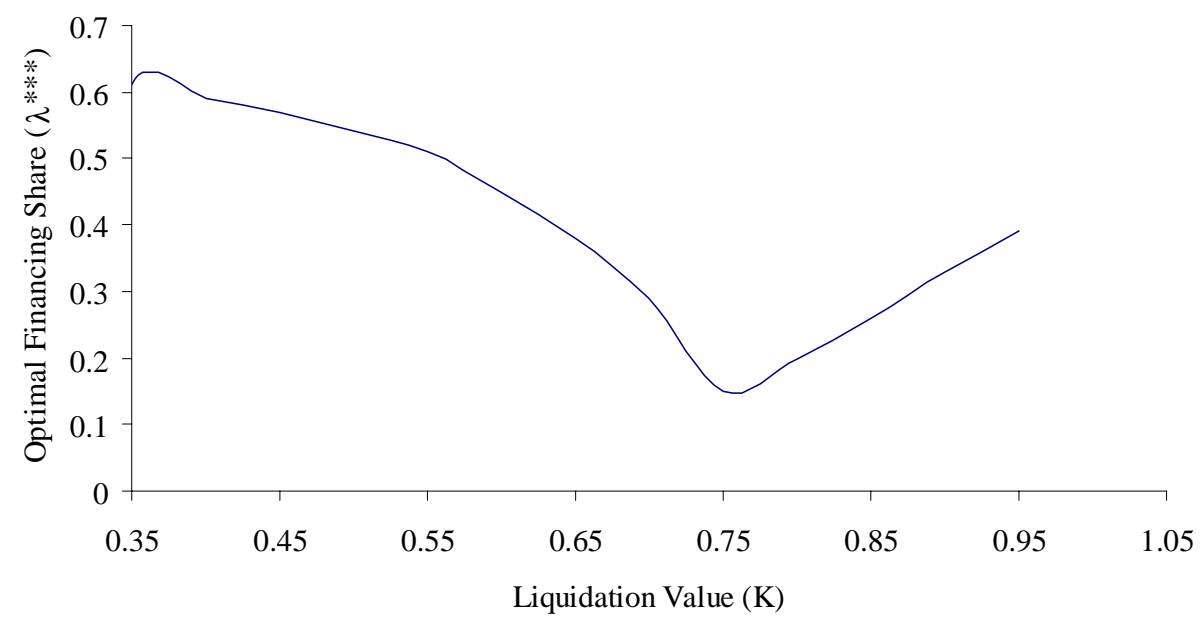

As becomes evident from Figure 6, the association between the financing share and $K$ is indeed non-linear and even non-monotonic. Hence, when using a cross-section of firms with heterogeneous asset liquidation values, this pattern can explain the seemingly contradictory pattern in empirical studies. Depending on the sample composition, the average correlation between a relationship lender's financing share (or correlated variables) and collateral can be positive or negative. 


\section{Asymmetric Information and the Relation- ship Lender's Information Privilege}

The preceding discussion has shown that under some conditions the co-existence of arm's-length and relationship financing can endogenously be the optimal financing choice of firms. It is interesting to note that relationship lending can be beneficial even without an active role as a firm's monitor. The ability to renegotiate loan contracts generates value. Joint financing from small banks and one relationship lender balances the relationship lenders' bargaining power and debt forgiveness. This corresponds to the analysis of Gorton and Kahn (2000), and is in the spirit of the theoretical literature discussing the optimal maturity structure of loan contracts (Hart (2001) and Diamond (2004)).

By abstracting from monitoring and private information, however, we ignore one essential part of the relationship lending concept, which also explains bargaining power of the relationship lender endogenously (Rajan (1992)). Yet, it is straightforward to show that imperfect signals and an information privilege of the large lender do not alter our qualitative results.

The framework which can be used to this end is global games, an equilibrium refinement developed by Carlsson and van Damme (1993). ${ }^{6}$ Relying on this framework, Corsetti, Dasgupta, Morris, and Shin (2000) have shown that the presence of a large player with an informational advantage eases the coordination problem and leads small players to change their thresholds for engaging in the risky action towards the efficient solution.

The global games solution introduces noisy signals about the state of nature, here the firm's cash flow. To illustrate the idea, assume the large lender still knows the true realization of $\theta$ but small lenders' information is $x^{i}=\theta+u^{i}$. Error terms $u^{i}$ are pairwise independent for $i \neq j$ and have a uniform distribution in $[-\epsilon,+\epsilon]$. If $\epsilon$ is sufficiently small, there is a unique equilibrium with thresholds $x^{*}$ and $\theta^{*}$, such that a small lender extends credit, if and only if $x^{i} \geq x^{*}$, and the large lender extends credit if and only if $\theta \geq \theta^{*}$. $\theta^{*}$ is also the default point of the firm.

\footnotetext{
${ }^{6}$ Global games have recently been applied to the coordination problem of refinancing in Morris and Shin (2001) and Hubert and Schäfer (2002) and perform quite well in experiments on coordination games, see Heinemann (2002).
} 
For the case of $\epsilon \rightarrow 0$, thresholds $x^{*}$ and $\theta^{*}$ converge to each other and approach

$$
\theta^{*}=V+D-\lambda(D-K)+(1-\lambda) K(W / D-1)
$$

As in our previous analysis, the default point decreases in the relationship lender's financing share:

$$
\frac{\mathrm{d} \theta^{*}}{\mathrm{~d} \lambda}=-(D-K)-K(W / D-1)<0 .
$$

Comparing the default point of the global games solution with default points for efficient and (most) inefficient coordination shows that $\underline{\theta}<\theta^{*}<\bar{\theta}$ and

$$
\frac{\mathrm{d} \bar{\theta}}{\mathrm{d} \lambda}<\frac{\mathrm{d} \theta^{*}}{\mathrm{~d} \lambda}<\frac{\mathrm{d} \underline{\theta}}{\mathrm{d} \lambda}
$$

Hence, similar to the case of inefficient coordination in Section 2.2, even if one abstracts from the risk premia reduction that the existence of the large lender induces because of his debt forgiveness, an asymmetric financing structure can be beneficial, but the optimal $\lambda$ will be smaller than in the case with inefficient coordination. Furthermore, the positive effect of relationship lending on prior expected payoffs is also somewhere between the two cases analyzed above, while the negative effect stemming from the hold-up problem does not depend on the efficiency of coordination. Therefore, we may expect intermediate solutions for the optimal size as well.

\section{Conclusions}

We have examined the optimal debt structure in a model that allows for multiple but asymmetric bank financing. This has been motivated by the empirical stylized fact that firms rely on multiple banks as financiers, where one can be special in the sense of relationship lending.

In our framework it can be optimal for entrepreneurs to finance their project by a multitude of equal and individually small banks who are unable to coordinate their decisions and a relationship bank with a high financing share and bargaining power. The presence of both lender types helps to optimally balance coordination risk and the hold-up-problem. Interestingly, especially firms with a high asset specificity (a high expected loss given default from the banks' perspective) or 
with low expected cash flows prefer a financing arrangement that is characterized by the co-existence of arm's length financiers and a relationship bank.

Our discussion of comparative statics offers an explanation for the contradictory evidence with respect to the association of relationship lending and loan collateralization. The model predicts a non-monotonic association between asset liquidation values (collateral value) and the importance of the relationship lender. Accordingly, depending on the sample at hand in a cross-sectional study, a positive or negative correlation can be observed empirically.

Finally, the model offers a framework to analyze strategic choices of the borrower and the corresponding impact on the debt structure. For instance, one interesting problem arises if the borrower can increase the risk of an investment project (i.e. asset substitution). Another extension would be to allow for an endogenous (i.e. strategic) distribution of information by the borrower. These issues must be left for future research. 


\section{Appendix A: Proof of Theorem 2}

Small lenders' participation constraint $\lambda_{S}$ is a function in $D$ with the following properties: At $D=R$

$$
\lambda_{S}(D=R)=\frac{V+R-\mu+\tau}{R-K}>1 .
$$

With rising $D, \lambda_{S}$ is first decreasing below 1 and then increasing to one as $D \rightarrow \infty$.

$$
\begin{gathered}
\lambda_{S}>1 \Leftrightarrow D<D_{1}=K+\frac{2 \tau(R-K)}{\mu+\tau-V-K}, \\
\frac{\partial \lambda_{S}}{\partial D}=\frac{(D-K)^{2}+(D-K)[\mu+\tau-V-D]-4 \tau(R-K)}{(D-K)^{3}}, \\
\frac{\partial \lambda_{S}}{\partial D}<0 \Leftrightarrow D<D_{2}=K+\frac{4 \tau(R-K)}{\mu+\tau-V-K}, \quad D_{2}>D_{1} .
\end{gathered}
$$

From (12) we see that $\lambda_{S}$ is rising in $R$. The higher the opportunity costs of small lenders, the higher is the requirement on the size of the large lender. If

$$
R<R_{0}=K+\frac{1}{8 \tau}(\mu+\tau-V-K)^{2},
$$

then $\lambda_{s}$ falls below zero before rising again.

$$
\lambda_{S}<0 \Leftrightarrow D \in\left(\frac{\mu+\tau-V+K}{2} \pm \sqrt{\frac{(\mu+\tau-V-K)^{2}}{4}-2 \tau(R-K)}\right) .
$$

Denote the lower end of this interval by $D_{5}$. If the firm chooses financing by small lenders only $(\lambda=0)$, then it will offer a repayment of $D_{5}$. Rising $R$ shifts the participation constraint up, so that with sufficiently high opportunity costs $\left(R>R_{0}\right)$ a relationship lender becomes necessary to attract small lenders.

For the large lender's participation constraint we must distinguish two cases:

1. If

$$
R>R_{2}=K+\frac{W^{*}-K}{2 \tau}\left[\mu+\tau-V-\frac{W^{*}+K}{2}\right]
$$

the partial derivative $\frac{\partial \lambda_{L}}{\partial D}$ is negative for all $D \neq \frac{W^{*}+K}{2}$. The second derivative is negative for $D<\frac{W^{*}+K}{2}$ and positive for $D>\frac{W^{*}+K}{2}$. For $D>\frac{W^{*}+K}{2}$, participation requires $\lambda>\lambda_{L}(D)>1$, which cannot be fulfilled. For $D \rightarrow-\infty$ or $D \rightarrow \infty, \lambda_{L}$ approaches 1 . For $D \nearrow \frac{W^{*}+K}{2}, \lambda_{L}$ approaches minus infinity. For $D \searrow \frac{W^{*}+K}{2}, \lambda_{L}$ approaches plus infinity (see Figure ??a above). 
2. If $R<R_{2}$, the partial derivative $\frac{\partial \lambda_{L}}{\partial D}$ is positive for all $D \neq \frac{W^{*}+K}{2}$. The second derivative is positive for $D<\frac{W^{*}+K}{2}$ and negative for $D>\frac{W^{*}+K}{2}$. If $D<\frac{W^{*}+K}{2}$, participation requires $\lambda<\lambda_{L}(D)$, while $\lambda_{L}(D)>1$. Here, the large lender accepts any share. For $D \rightarrow-\infty$ or $D \rightarrow \infty, \lambda_{L}$ approaches 1 . For $D \nearrow \frac{W^{*}+K}{2}, \lambda_{L}$ approaches infinity. For $D \searrow \frac{W^{*}+K}{2}, \lambda_{L}$ approaches minus infinity.

In the first case participation of the large lender requires $\lambda<\lambda_{L}(D)$ and $D<\frac{W^{*}+K}{2}$. In the second case the large lender requires $\lambda>\lambda_{L}(D)$ or $D<\frac{W^{*}+K}{2}$.

We cannot derive an explicit solution for the optimal size of the large lender. We will use a partition of the parameter space to characterize the conditions for which the firm chooses asymmetric financing and those for which the firm is financed by small lenders only, by single large lender, or not at all. The borders between these regions are hyperplanes that can be described by functions that represent $R$ depending on the other parameters.

$$
\begin{aligned}
& R_{0}=K+\frac{1}{8 \tau}(\mu+\tau-V-K)^{2}, \\
& R_{1}=K+\frac{W^{*}-K}{4 \tau}(\mu+\tau-V-K), \\
& R_{2}=K+\frac{W^{*}-K}{2 \tau}\left[\mu+\tau-V-\frac{W^{*}+K}{2}\right], \\
& R_{4}=K+\frac{W-K}{2 \tau}(\mu+\tau-V-K), \\
& R_{5}=K+\frac{W^{* 2}}{\tau}\left[\sqrt{\left.1+\frac{(\mu+\tau-V-K)^{2}}{4 W^{* 2}}-1\right]},\right. \\
& R_{6}=K+\frac{W-K}{2 \tau}(\mu+\tau-V-W) .
\end{aligned}
$$

In addition, we need critical values for $\mu$, defined as

$$
\begin{aligned}
& \mu_{1}=V-\tau+W^{*}+\frac{W^{*}-K}{\sqrt{2}-1}, \\
& \mu_{2}=V-\tau+2 W-K . \\
& \mu_{3}=V-\tau+K+\frac{\left(W^{*}-K\right)^{2}}{2\left(W^{*}-W\right)} .
\end{aligned}
$$


Using these definitions, Theorem 2 can be restated as follows.

\section{Theorem 2}

a) The firm can be financed if and only if $R<R_{2}$.

b) The firm is financed by a single large lender $(\lambda=1)$, if and only if $R_{4} \leq R \leq$ $R_{2} . R_{4} \leq R_{2}$ requires $\mu \geq \mu_{3}$ and $W^{*}-W>\frac{\left(W^{*}-K\right)^{2}}{4 \tau}$.

c) There is an intermediate region for $R-K$, for which the optimal financing structure is asymmetric. For $\mu<\mu_{2}$ there is asymmetric financing, whenever $R_{5}<R<R_{2}$. For $\mu>\mu_{2}$ there is asymmetric financing, whenever $\min \left\{R_{5}, R_{6}\right\}<R<\min \left\{R_{2}, R_{4}\right\}$. Both regions have a non-empty interior.

d) For sufficiently low $R-K$, the firm is financed by small lenders only $(\lambda=0)$. For $\mu<\mu_{2}, \lambda=0$ whenever $R<R_{5}$. For $\mu>\mu_{2}, \lambda=0$ if $R<\min \left\{R_{5}, R_{6}\right\}$.

e) The critical values of $R-K$ at which the firm gets financed from any type of lender are monotonically increasing in $\mu$ and decreasing in $V$.

The proof combines a series of lemmas.

Lemma 1 (i) $R_{2}, R_{4}$ and $R_{6}$ are linear in $\mu$. If $W^{*}>W$, then $R_{2}$ is steeper than $R_{4}$ and $R_{6}$,

(ii) $R_{4}>R_{6}$,

(iii) $R_{2}>R_{1}$,

(iv) $R_{0}$ and $R_{5}$ are convex in $\mu$,

(v) $R_{0} \geq R_{6}$ and $R_{0}=R_{6}$ if and only if $\mu=\mu_{2}$

(vi) $R_{0}>R_{5}$, and

(vii) $R_{2}>R_{6}$.

Proof: (i) is obvious from definitions of $R_{2}, R_{4}$ and $R_{6}$, and (ii) follows from $W>K$.

(iii) $R_{2}>R_{1}$ is equivalent to

$$
2\left(\mu+\tau-V-\left(W^{*}+K\right) / 2\right)>\mu+\tau-V-K \quad \Leftrightarrow \quad \mu+\tau-V-W^{*}>0 .
$$

The last inequality is our assumption on the upper bound of the prior distribution's support.

(iv) Convexity of $R_{0}$ is obvious from the quadratic form. Convexity of $R_{5}$ 
requires $\frac{\partial^{2} R_{5}}{\partial^{2} \mu}>0$

$\frac{\partial R_{5}}{\partial \mu}=\frac{(\mu+\tau-V-K)}{4 \tau \sqrt{1+\frac{(\mu+\tau-V-K)^{2}}{4 W^{* 2}}}} \Rightarrow \frac{\partial^{2} R_{5}}{\partial^{2} \mu}=\frac{1}{4 \tau} \frac{\sqrt{\cdot}-\frac{(\mu+\tau-V-K)^{2}}{4 W^{* 2} \sqrt{\cdot}}}{(\sqrt{\cdot})^{2}}=\frac{1}{4 \tau(\sqrt{\cdot})^{3}}>0$

$(\mathrm{v})$

$$
\begin{gathered}
R_{0} \geq R_{6} \Leftrightarrow \quad \Leftrightarrow \quad(\mu+\tau-V-K)^{2} \geq 4(W-K)(\mu+\tau-V-W) \\
\Leftrightarrow \quad(\mu+\tau-V+K-2 W)^{2}+4(W-K)(\mu+\tau-V-K)-4(W-K)^{2} \\
\geq 4(W-K)(\mu+\tau-V-W) \\
\Leftrightarrow \quad(\mu+\tau-V+K-2 W)^{2} \geq 0 .
\end{gathered}
$$

(vi)

$$
R_{0}>R_{5} \Leftrightarrow \frac{(\mu+\tau-V-K)^{2}}{8 W^{* 2}}>\sqrt{1+\frac{(\mu+\tau-V-K)^{2}}{4 W^{* 2}}}-1 .
$$

Define $A=\frac{(\mu+\tau-V-K)^{2}}{8 W^{* 2}}$. Then

$$
R_{0}>R_{5} \quad \Leftrightarrow \quad A-\sqrt{1+2 A}+1>0
$$

For $A=0$, the left hand side equals zero. Furthermore, the left hand side is increasing in $A$. Since $A>0$, we find that $R_{0}>R_{5}$.

(vii) $R_{2}$ and $R_{6}$ are both linear increasing in $\mu . R_{6}$ is flatter. Hence, it is sufficient to show that $R_{6}<R_{2}$ for the lowest possible $\mu=W^{*}+V-\tau$. Here, $R_{0}<R_{2}$. Since $R_{6} \leq R_{0}$ from (v), it follows that $R_{6}<R_{2}$. QED

Lemma $2 R_{0}<R_{2}$ is equivalent to $\mu<\mu_{1}$.

Proof:

$$
\begin{gathered}
R_{0}<R_{2} \Leftrightarrow\left(W^{*}-K\right)\left[\mu+\tau-V-\frac{W^{*}+K}{2}\right]>\frac{1}{4}[\mu+\tau-V-K]^{2}(26) \\
\Leftrightarrow \quad 4(\mu+\tau-V)\left(W^{*}-K\right)-2\left(W^{*}+K\right)\left(W^{*}-K\right) \\
\quad>(\mu+\tau-V)^{2}-2(\mu+\tau-V) K+K^{2} \\
\Leftrightarrow \quad 4(\mu+\tau-V) W^{*}-2(\mu+\tau-V) K-2 W^{* 2}+K^{2}>(\mu+\tau-V)^{2}
\end{gathered}
$$




$$
\begin{aligned}
& \Leftrightarrow \quad(\mu+\tau-V)^{2}-2(\mu+\tau-V) K+K^{2}>2(\mu+\tau-V)^{2}-4(\mu+\tau-V) W^{*}+2 W^{* 2} \\
& \Leftrightarrow \quad(\mu+\tau-V-K)^{2}>2\left(\mu+\tau-V-W^{*}\right)^{2} \\
& \Leftrightarrow \quad \mu+\tau-V-K>\sqrt{2}\left(\mu+\tau-V-W^{*}\right) \\
& \Leftrightarrow \quad \mu<\mu_{1}=V-\tau+W^{*}+\frac{W^{*}-K}{\sqrt{2}-1} .
\end{aligned}
$$

Lemma 3 For $R>R_{2}$, it is impossible to get financed with $\lambda>0$.

Proof: For $R>R_{2}$, the large lender provides capital only, when there are some small lenders and $D<\frac{W^{*}+K}{2}$. Asymmetric financing, however, is impossible if $\lambda_{S}(D)>1$ for all $D<\frac{W^{*}+K}{2}$. This is equivalent to

$$
\begin{aligned}
D_{1}>\frac{W^{*}+K}{2} & \Leftrightarrow 2 \tau(R-K)>\frac{W^{*}-K}{2}(\mu+\tau-V-K) \\
\Leftrightarrow & R>R_{1}=K+\frac{W^{*}-K}{4 \tau}(\mu+\tau-V-K)
\end{aligned}
$$

Since $R_{2}>R_{1}$, it is not possible to get asymmetric financing either.

QED

For $R<R_{0}$ small lenders are willing to finance the project without relationship bank, provided that $D \geq D_{5}$. The required payment $D_{5}$ may, however, be higher than costs of refinancing. If the firm has the option to drive out small lenders at the stage of the refinancing game and replace them with new creditors at this stage, then promised payments $D>W$ are not credible, since it is cheaper to replace them if the project generates a sufficiently high payoff, while otherwise the firm goes bankrupt.

Lemma $4 D_{5}<W$ if and only if

$$
\mu<\mu_{2}=V-\tau+2 W-K \quad \vee \quad R<R_{6}
$$

Proof: From Lemma $1(\mathrm{v})$ we know that $R_{6} \leq R_{0}$. Thereby, $R \leq R_{6}$ implies existence of $D_{5}$.

$$
\begin{aligned}
& D_{5}=\frac{\mu+\tau-V+K}{2}-\sqrt{\frac{(\mu+\tau-V-K)^{2}}{4}-2 \tau(R-K)}<W \\
\Leftrightarrow & \frac{\mu+\tau-V-2 W+K}{2}<\sqrt{\frac{(\mu+\tau-V-K)^{2}}{4}-2 \tau(R-K)}
\end{aligned}
$$


$\Leftrightarrow \quad \mu<\mu_{2} \quad \vee \quad \frac{(\mu+\tau-V-2 W+K)^{2}}{4}<\frac{(\mu+\tau-V-K)^{2}}{4}-2 \tau(R-K)$

The second inequality is equivalent to

$$
\begin{array}{cc} 
& 2 \tau(R-K)<\frac{1}{4}\left[(\mu+\tau-V-K)^{2}-(\mu+\tau-V-2 W+K)^{2}\right] \\
\Leftrightarrow \quad & (R-K)<\frac{1}{8 \tau}\left[(\mu+\tau-V)^{2}-2(\mu+\tau-V) K+K^{2}\right. \\
& \left.-(\mu+\tau-V)^{2}+2(\mu+\tau-V)(2 W-K)-(2 W-K)^{2}\right] \\
\Leftrightarrow \quad & R<K+\frac{1}{8 \tau}\left[K^{2}+2(\mu+\tau-V)(2 W-2 K)-\left(4 W^{2}-4 W K+K^{2}\right)\right] \\
\Leftrightarrow \quad & R<R_{6}=K+\frac{W-K}{2 \tau}(\mu+\tau-V-W) .
\end{array}
$$

QED

\section{Lemma $5 \quad \mu_{1}>\mu_{2}$.}

Proof:

$$
\begin{aligned}
\mu_{1}>\mu_{2} & \Leftrightarrow \quad W^{*}+\frac{W^{*}-K}{\sqrt{2}-1}>2 W-K \\
& \Leftrightarrow \quad\left(W^{*}-K\right)+\left(1+\frac{1}{\sqrt{2}-1}\right)>2(W-K) \\
& \Leftrightarrow \quad \frac{W^{*}-K}{W-K}>2-\sqrt{2} .
\end{aligned}
$$

Since $W^{*} \geq W$ and $2-\sqrt{2}<1$, this implies $\mu_{1}>\mu_{2}$.

Lemma 6 For $R>R_{2}$ the firm cannot be financed.

Proof: From Lemma 3 we know that for $R>R_{2}$ the firm cannot get a large lender. Small lenders are willing to finance the whole project if $R \leq R_{0}$ and $D \geq D_{5}$. Lemma 2 tells us that $R_{2}<R \leq R_{0}$ requires $\mu>\mu_{1}$. ¿From Lemma 5 we know that $\mu_{1}>\mu_{2}$. Hence, Lemma 4 implies that $D_{5}<W$ requires $R<R_{6}$. However, Lemma 1 (vii) tells us that $R_{6}<R_{2}$. Thereby, $R>R_{2}$ implies that small lenders are not willing to finance the whole project at a promised repayment $D<W$.

QED

If $R \leq R_{2}$, the large lender is willing to finance the whole project. Thus, the project is financed if and only if $R \leq R_{2}$. This establishes the first part of the theorem. 
Lemma 7 For $R_{4} \leq R \leq R_{2}$, the optimal financing structure implies $\lambda=1$.

This case can only occur if $R_{4} \leq R_{2}$, which is equivalent to $\mu \geq \mu_{3}$ and requires $W^{*}-W>\frac{\left(W^{*}-K\right)^{2}}{4 \tau}$.

Proof: If $R<R_{2}$, the large lender is willing to finance the whole project or a large part of it. Small lenders are willing to provide funds if and only if $D_{1}<D \leq W$. Lower repayments violate the participation constraint and higher repayments are not credible, because then, the firm would replace small lenders at stage $4 . D_{1}<W$ is equivalent to

$$
\begin{aligned}
& 2 \tau(R-K)<(W-K)(\mu+\tau-V-K) \\
& \Leftrightarrow \quad R<R_{4}=K+\frac{W-K}{2 \tau}(\mu+\tau-V-K) .
\end{aligned}
$$

Thus, for $R_{4} \leq R \leq R_{2}$ small lenders are not willing to provide funds.

This case requires $R_{4} \leq R_{2}$, which is equivalent to

$$
\begin{aligned}
& (W-K)[\mu+\tau-V-K] \leq\left(W^{*}-K\right)\left[\mu+\tau-V-K-\frac{W^{*}-K}{2}\right] \\
\Leftrightarrow & \left(W^{*}-W\right)[\mu+\tau-V-K] \geq \frac{\left(W^{*}-K\right)^{2}}{2} \Leftrightarrow \mu \geq \mu_{3} .
\end{aligned}
$$

Basic assumptions require $\mu<\tau+V+K$. Thereby, existence of this case requires $\mu_{3}<\tau+V+K$, which is equivalent to $W^{*}-W>\frac{\left(W^{*}-K\right)^{2}}{4 \tau}$.

Lemma 7 establishes the second part of the theorem and calls for some economic rationale: If the firm could commit to pay small lenders more than $W$, then small lenders would be willing to provide funds. Moreover, firm's expected profits would increase, because the promised repayment could be lower than $W^{*}$, which is the amount that the large lender extracts anyway. If such a commitment is not possible, then small lenders will not provide funds, because the maximum credible repayment is too low to cover the default risk. The large lender, however, is willing to provide funds, because he knows that he can extract up to $W^{*}$, whenever the firm's cash flow is high enough. This is the only case in which the firm is financed by a single large lender. If costs of refinancing do not depend on the size of the credit, i.e. $W^{*}=W$, the firm will never choose $\lambda=1$.

Lemma 8 For $R \leq R_{2}$ and $R<R_{4}$ the optimal financing structure does always imply $\lambda<1$. 
Proof: At $\lambda=1$, the firm's iso-profit-curves are horizontal (see Figure 4). Thus, the firm would prefer an asymmetric debt structure if it is possible to attract small lenders at any $D \leq W$. This requires $D_{1}<W$ which is equivalent to $R<R_{4}$.

QED

Lemma 9 For $R_{0}<R \leq R_{2}$, the optimal financing structure implies $\lambda>0$.

Proof: For $R_{0}<R \leq R_{2}$, the large lender is willing to finance the whole project or a sufficiently large part of it. Small lenders are not willing to finance the project without relationship bank. Hence, any solution implies $\lambda>0$. QED

Lemma 10 If $R_{6}<R \leq R_{2}$ and $\mu>\mu_{2}$, the optimal financing structure implies $\lambda>0$.

Proof: For $\mu>\mu_{2}$ and $R>R_{6}$, we know from Lemma 4 that small lenders are not willing to finance the project without relationship bank at any $D \leq W$.

QED

Lemma $11 \mu<\mu_{2}$ implies $R_{2}<R_{4}$.

Proof: $\mu<\mu_{2}$ implies

$$
\left(W^{*}-W\right)(\mu+\tau-V-K)<2\left(W^{*}-W\right)(W-K) .
$$

$R_{2}<R_{4}$ is equivalent to

$$
\begin{aligned}
& \left(W^{*}-K\right)\left(\mu+\tau-V-K-\frac{W^{*}-K}{2}\right)<(W-K)(\mu+\tau-V-K) \\
& \Leftrightarrow \quad\left(W^{*}-W\right)(\mu+\tau-V-K)<\frac{\left(W^{*}-K\right)^{2}}{2} . \\
& \Leftrightarrow \quad 2\left(W^{*}-W\right)(W-K)<\frac{\left(W^{*}-K\right)^{2}}{2} \\
& \Leftrightarrow \quad 4\left(W^{*}-W\right)(W-K)<\left(W^{*}-W+W-K\right)^{2} \\
& \Leftrightarrow \quad 4\left(W^{*}-W\right)(W-K)<\left(W^{*}-W\right)^{2}+2\left(W^{*}-W\right)(W-K)+(W-K)^{2} \\
& \Leftrightarrow \quad 2\left(W^{*}-W\right)(W-K)<\left(W^{*}-W\right)^{2}+(W-K)^{2} \\
& \Leftrightarrow \quad 0<\left(\left(W^{*}-W\right)-(W-K)\right)^{2}=\left(W^{*}+K\right)^{2} .
\end{aligned}
$$


Lemma 12 If $R_{5}<R<\min \left\{R_{0}, R_{2}\right\}$, then $\lambda>0$.

Proof: $D_{5}$ is increasing in $R$. Therefore, $R<R_{0}$ implies $D_{5}(R)<D_{5}\left(R_{0}\right)=$ $\frac{\mu+\tau-V+K}{2}$. This is smaller than $\frac{W^{*}+K}{2}$, because $\mu+\tau<W^{*}+V$. For $R<R_{2}$ the large lender accepts any share in the debt, provided that $D<\frac{W^{*}+K}{2}$. Thus, his participation constraint is not binding, and the firm chooses $\lambda>0$ if and only if the iso-profit curve at $\left(D_{5}, \lambda=0\right)$ is steeper than $\lambda_{S}$. The firm's iso-profit curve at $D_{5}$ is steeper than $\lambda_{S}$ if and only if

$$
-\left.\frac{\partial \lambda\left(D_{5}\right)}{\partial D}\right|_{\mathrm{E}\left(\pi_{F}\right)=\text { const. }}>-\frac{\partial \lambda_{S}\left(D_{5}\right)}{\partial D}
$$

where

$$
\begin{aligned}
& \frac{\partial \lambda_{S}}{\partial D}=\frac{(D-K)^{2}+(D-K)[\mu+\tau-V-D]-4 \tau(R-K)}{(D-K)^{3}} \\
& =\frac{(D-K)^{2}-(D-K)[\mu+\tau-V-D]+2(D-K)[\mu+\tau-V-D]-4 \tau(R-K)}{(D-K)^{3}} \\
& =\frac{(D-K)-[\mu+\tau-V-D]}{(D-K)^{2}}-\frac{2 \lambda_{S}(D)}{(D-K)} .
\end{aligned}
$$

Then, (28) is equivalent to

$$
\begin{aligned}
& \frac{1}{W^{*}-D_{5}}>\frac{\mu+\tau-V+K-2 D_{5}}{\left(D_{5}-K\right)^{2}} \\
& \Leftrightarrow \quad\left(D_{5}-K\right)^{2}>\left(W^{*}-D_{5}\right)\left(\mu+\tau-V+K-2 D_{5}\right) \\
& \Leftrightarrow \quad\left[\frac{\mu+\tau-V-K}{2}-\sqrt{\frac{(\mu+\tau-V-K)^{2}}{4}-2 \tau(R-K)}\right]^{2}>\left(W^{*}-D_{5}\right) 2 \sqrt{\cdot} \\
& \Leftrightarrow \quad \frac{(\mu+\tau-V-K)^{2}}{2}-[\mu+\tau-V-K] \sqrt{\cdot}-2 \tau(R-K) \\
& \quad>\left[W^{*}-\frac{\mu+\tau-V+K}{2}+\sqrt{\cdot}\right] 2 \sqrt{\cdot} \\
& \quad=2 W^{*} \sqrt{\cdot}-[\mu+\tau-V-K] \sqrt{\cdot}+\frac{(\mu+\tau-V-K)^{2}}{2}-4 \tau(R-K) \\
& \Leftrightarrow \quad 0>2 W^{*} \sqrt{\cdot}-2 \tau(R-K)
\end{aligned}
$$




$$
\begin{aligned}
& \Leftrightarrow \quad \tau(R-K)>W^{*} \sqrt{\cdot} \\
& \Leftrightarrow \quad \tau^{2}(R-K)^{2}>W^{* 2}\left[\frac{(\mu+\tau-V-K)^{2}}{4}-2 \tau(R-K)\right] \\
& \Leftrightarrow \quad \tau^{2}(R-K)^{2}+2 \tau(R-K) W^{* 2}+W^{* 4}>W^{* 4}+W^{* 2} \frac{(\mu+\tau-V-K)^{2}}{4} \\
& \Leftrightarrow \quad \tau(R-K)+W^{* 2}>\sqrt{W^{* 4}+W^{* 2} \frac{(\mu+\tau-V-K)^{2}}{4}} \\
& \Leftrightarrow \quad R>R_{5}=K+\frac{W^{* 2}}{\tau}\left[\sqrt{1+\frac{(\mu+\tau-V-K)^{2}}{4 W^{* 2}}}-1\right]
\end{aligned}
$$

Lemma 13 There is an intermediate region for $R$, for which the optimal financing structure is asymmetric, i.e. $0<\lambda<1$. For $\mu<\mu_{2}$, there is asymmetric financing, whenever $R_{5}<R<R_{2}$. For $\mu>\mu_{2}$ there is asymmetric financing, whenever $\min \left\{R_{5}, R_{6}\right\}<R<\min \left\{R_{2}, R_{4}\right\}$. Both regions have a non-empty interior.

Proof: From Lemma 1 we know that $R_{6}<R_{4}$ and $R_{6}<R_{2}$. For $\mu>\mu_{2}$ Lemma 8, 12 and 10 imply $0<\lambda<1$ for $\min \left\{R_{5}, R_{6}\right\}<R<\min \left\{R_{2}, R_{4}\right\}$. For $\mu<\mu_{2}$, Lemma 11 implies $R_{2}<R_{4}$ and Lemma 2 and 5 imply $R_{0}<R_{2}$. Here, Lemma 8, 9 and 12 imply $0<\lambda<1$ for $R_{5}<R<R_{2}$.

QED

This establishes the third part of the theorem.

Lemma 14 The optimal financing structure is $D=D_{5}$ and $\lambda=0$, if either

(i) $\mu \leq \mu_{2}$ and $R \leq R_{5}$

or

(ii) $\mu>\mu_{2}$ and $R \leq \min \left\{R_{5}, R_{6}\right\}$

Proof: If the iso-profit curve at $\left(D_{5}, \lambda=0\right)$ is not steeper than $\lambda_{S}$, then it is optimal to choose $D=D_{5}$ and $\lambda=0$ provided that $D_{5} \leq W$, which requires $R \leq R_{6}$ or $\mu \leq \mu_{2}$ by Lemma 4 . The proof of Lemma 12 implies that for $R<R_{5}$ the iso-profit curve at $\left(D_{5}, \lambda=0\right)$ is not steeper than $\lambda_{S}$.

QED

This establishes the fourth part of the theorem. The borders between the different financing structures are continuous in all parameters and defined by parts of the functions $R_{0}$ to $R_{6}$. These functions are monotonically increasing in $\mu$ and decreasing in $V$. This completes the proof of Theorem 2. 


\section{References}

Berger, Allen N., and Gregory F. Udell, 1995, Relationship Lending and Lines of Credit in Small Firm Finance, Journal of Business 68, 351-381.

Bolton, Patrick, and David S. Scharfstein, 1996, Optimal Debt Structure and the Number of Creditors, Journal of Political Economy 104, 1-25.

Boot, Arnoud W., 2000, Relationship Banking: What do we know?, Journal of Financial Intermedation 9, 7-25.

Carletti, Elena, 2004, The structure of bank relationships, endogenous monitoring, and loan rates, Journal of Financial Intermediation 13, 58-86.

Carlsson, Hans, and Eric van Damme, 1993, Global Games and Equilibrium Selection, Econometrica 61, 989-1018.

Corsetti, Giancarlo, Amil Dasgupta, Stephen Morris, and Hyun Song Shin, 2000, Does one Soros Make a Difference? A Theory of Currency Crises with Large and Small Traders, Working Paper, Yale University.

Degryse, Hans, and Patrick van Cayseele, 2000, Relationship lending within a bank-based system: Evidence from European small business data, Journal of Financial Intermediation 9, 90-109.

Detragiache, Enrica, Paolo Garella, and Luigi Guiso, 2000, Multiple vs. Single Banking Relationships: Theory and Evidence, Journal of Finance 55, 11331161.

Dewatripont, Mathias, and Eric Maskin, 1995, Credit and Efficiency in Centralized versus Decentralized Markets, Review of Economic Studies 62, 541-556.

Diamond, Douglas, 2004, Committing to Commit: Short-term Debt When Enforcement is Costly, Journal of Finance p. forthcoming.

Elsas, Ralf, 2004, Empirical Determinants of Relationship Lending, Journal of Financial Intermediation p. forthcoming. 
Elsas, Ralf, and Jan Pieter Krahnen, 1998, Is Relationship Lending Special? Evidence from Credit-File Data in Germany, Journal of Banking and Finance $22,1283-1316$.

Elsas, Ralf, and Jan Pieter Krahnen, 2002, Collateral, Relationship Lending, and Financial Distress: An Empirical Study on Financial Contracting, Working Paper, Goethe-Universität, Frankfurt.

Gorton, Gary, and James Kahn, 2000, The design of bank loan contracts, Review of Financil Studies 13, 331-364.

Harhoff, Dietmar, and Tim Körting, 1998, Lending Relationships in Germany Empirical Evidence from Survey Data, Journal of Banking and Finance 22, $1317-1353$.

Hart, Oliver, 2001, Financial Contracting, Journal of Economic Literature 34, 1079-1100.

Heinemann, Frank, 2002, Exchange Rate Attack as a Coordination Game: Theory and Experimental Evidence, Oxford Review of Economic Policy 18, 462478.

Holmström, Bengt, and Jean Tirole, 1997, Financial Intermediation, Loanable Funds, and the Real Sector, Quarterly Journal of Economics 112, 663-691.

Hubert, Franz, and Dorothea Schäfer, 2002, Coordination failure with multiple source lending: The cost of protection against a powerful lender, Journal of Institutional and Theroetical Economics 158, 256-275.

Mayer, Colin, 1988, New issues in Corporate Finance, European Economic Review $32,1167-1189$.

Morris, Stephen, and Hyun Song Shin, 2001, Coordination risk and the price of debt, Working Paper, Yale University.

Ongena, Steven, and David A. Smith, 2001, What Determines the Number of Bank Relationships? Cross-Country-Evidence, Journal of Financial Intermediation 9, 26-56. 
Pagratis, Spyros, 2002, Co-ordination failure and the role of banks in resolution of financial distress, Working Paper, London School of Economics.

Petersen, Mitchell A., and Raghuram G. Rajan, 1994, The Benefits of Lending Relationships: Evidence form Small Business Data, Journal of Finance 49, $3-37$.

Rajan, Raghuram G., 1992, Insiders and Outsiders: The Choice between Informed and Arm's Length Debt, Journal of Finance 50, 1113-1146.

Sharpe, Stephen A., 1990, Asymmetric Information, Bank Lending, and Implicit Contracts: A Stylized Model of Customer Relationships, Journal of Finance 45, 1069-1087.

von Thadden, Ernst-Ludwig, 1992, The commitment of finance, duplicated monitoring, and the investment horizon, Working Paper, CEPR No. 27, London.

von Thadden, Ernst-Ludwig, 1995, Long-term contracts, short-term investments and monitoring, Review of Economic Studies 62, 557-575.

Welch, Ivo, and Arturo Bris, 2001, The optimal concetration of creditors, Working Paper, Yale University. 


\section{CESifo Working Paper Series}

(for full list see www.cesifo.de)

1186 Jean-Pierre Ponssard, Rent Dissipation in Repeated Entry Games: Some New Results, May 2004

1187 Pablo Arocena, Privatisation Policy in Spain: Stuck Between Liberalisation and the Protection of Nationals' Interests, May 2004

1188 Günter Knieps, Privatisation of Network Industries in Germany: A Disaggregated Approach, May 2004

1189 Robert J. Gary-Bobo and Alain Trannoy, Efficient Tuition Fees, Examinations, and Subsidies, May 2004

1190 Saku Aura and Gregory D. Hess, What's in a Name?, May 2004

1191 Sjur Didrik Flåm and Yuri Ermoliev, Investment Uncertainty, and Production Games, May 2004

1192 Yin-Wong Cheung and Jude Yuen, The Suitability of a Greater China Currency Union, May 2004

1193 Inés Macho-Stadler and David Pérez-Castrillo, Optimal Enforcement Policy and Firms' Emissions and Compliance with Environmental Taxes, May 2004

1194 Paul De Grauwe and Marianna Grimaldi, Bubbles and Crashes in a Behavioural Finance Model, May 2004

1195 Michel Berne and Gérard Pogorel, Privatization Experiences in France, May 2004

1196 Andrea Galeotti and José Luis Moraga-González, A Model of Strategic Targeted Advertising, May 2004

1197 Hans Gersbach and Hans Haller, When Inefficiency Begets Efficiency, May 2004

1198 Saku Aura, Estate and Capital Gains Taxation: Efficiency and Political Economy Consideration, May 2004

1199 Sandra Waller and Jakob de Haan, Credibility and Transparency of Central Banks: New Results Based on Ifo's World Economicy Survey, May 2004

1200 Henk C. Kranendonk, Jan Bonenkamp, and Johan P. Verbruggen, A Leading Indicator for the Dutch Economy - Methodological and Empirical Revision of the CPB System, May 2004 
1201 Michael Ehrmann, Firm Size and Monetary Policy Transmission - Evidence from German Business Survey Data, May 2004

1202 Thomas A. Knetsch, Evaluating the German Inventory Cycle - Using Data from the Ifo Business Survey, May 2004

1203 Stefan Mittnik and Peter Zadrozny, Forecasting Quarterly German GDP at Monthly Intervals Using Monthly IFO Business Conditions Data, May 2004

1204 Elmer Sterken, The Role of the IFO Business Climate Indicator and Asset Prices in German Monetary Policy, May 2004

1205 Jan Jacobs and Jan-Egbert Sturm, Do Ifo Indicators Help Explain Revisions in German Industrial Production?, May 2004

1206 Ulrich Woitek, Real Wages and Business Cycle Asymmetries, May 2004

1207 Burkhard Heer and Alfred Maußner, Computation of Business Cycle Models: A Comparison of Numerical Methods, June 2004

1208 Costas Hadjiyiannis, Panos Hatzipanayotou, and Michael S. Michael, Pollution and Capital Tax Competition within a Regional Block, June 2004

1209 Stephan Klasen and Thorsten Nestmann, Population, Population Density, and Technological Change, June 2004

1210 Wolfgang Ochel, Welfare Time Limits in the United States - Experiences with a New Welfare-to-Work Approach, June 2004

1211 Luis H. R. Alvarez and Erkki Koskela, Taxation and Rotation Age under Stochastic Forest Stand Value, June 2004

1212 Bernard M. S. van Praag, The Connexion Between Old and New Approaches to Financial Satisfaction, June 2004

1213 Hendrik Hakenes and Martin Peitz, Selling Reputation When Going out of Business, June 2004

1214 Heikki Oksanen, Public Pensions in the National Accounts and Public Finance Targets, June 2004

1215 Ernst Fehr, Alexander Klein, and Klaus M. Schmidt, Contracts, Fairness, and Incentives, June 2004

1216 Amihai Glazer, Vesa Kanniainen, and Panu Poutvaara, Initial Luck, Status-Seeking and Snowballs Lead to Corporate Success and Failure, June 2004

1217 Bum J. Kim and Harris Schlesinger, Adverse Selection in an Insurance Market with Government-Guaranteed Subsistence Levels, June 2004 
1218 Armin Falk, Charitable Giving as a Gift Exchange - Evidence from a Field Experiment, June 2004

1219 Rainer Niemann, Asymmetric Taxation and Cross-Border Investment Decisions, June 2004

1220 Christian Holzner, Volker Meier, and Martin Werding, Time Limits on Welfare Use under Involuntary Unemployment, June 2004

1221 Michiel Evers, Ruud A. de Mooij, and Herman R. J. Vollebergh, Tax Competition under Minimum Rates: The Case of European Diesel Excises, June 2004

1222 S. Brock Blomberg and Gregory D. Hess, How Much Does Violence Tax Trade?, June 2004

1223 Josse Delfgaauw and Robert Dur, Incentives and Workers' Motivation in the Public Sector, June 2004

1224 Paul De Grauwe and Cláudia Costa Storti, The Effects of Monetary Policy: A MetaAnalysis, June 2004

1225 Volker Grossmann, How to Promote R\&D-based Growth? Public Education Expenditure on Scientists and Engineers versus R\&D Subsidies, June 2004

1226 Bart Cockx and Jean Ries, The Exhaustion of Unemployment Benefits in Belgium. Does it Enhance the Probability of Employment?, June 2004

1227 Bertil Holmlund, Sickness Absence and Search Unemployment, June 2004

1228 Klaas J. Beniers and Robert Dur, Politicians' Motivation, Political Culture, and Electoral Competition, June 2004

1229 M. Hashem Pesaran, General Diagnostic Tests for Cross Section Dependence in Panels, July 2004

1230 Wladimir Raymond, Pierre Mohnen, Franz Palm, and Sybrand Schim van der Loeff, An Empirically-Based Taxonomy of Dutch Manufacturing: Innovation Policy Implications, July 2004

1231 Stefan Homburg, A New Approach to Optimal Commodity Taxation, July 2004

1232 Lorenzo Cappellari and Stephen P. Jenkins, Modelling Low Pay Transition Probabilities, Accounting for Panel Attrition, Non-Response, and Initial Conditions, July 2004

1233 Cheng Hsiao and M. Hashem Pesaran, Random Coefficient Panel Data Models, July 2004

1234 Frederick van der Ploeg, The Welfare State, Redistribution and the Economy, Reciprocal Altruism, Consumer Rivalry and Second Best, July 2004 
1235 Thomas Fuchs and Ludger Woessmann, What Accounts for International Differences in Student Performance? A Re-Examination Using PISA Data, July 2004

1236 Pascalis Raimondos-Møller and Alan D. Woodland, Measuring Tax Efficiency: A Tax Optimality Index, July 2004

1237 M. Hashem Pesaran, Davide Pettenuzzo, and Allan Timmermann, Forecasting Time Series Subject to Multiple Structural Breaks, July 2004

1238 Panu Poutvaara and Andreas Wagener, The Invisible Hand Plays Dice: Eventualities in Religious Markets, July 2004

1239 Eckhard Janeba, Moral Federalism, July 2004

1240 Robert S. Chirinko, Steven M. Fazzari, and Andrew P. Meyer, That Elusive Elasticity: A Long-Panel Approach to Estimating the Capital-Labor Substitution Elasticity, July 2004

1241 Hans Jarle Kind, Karen Helene Midelfart, Guttorm Schjelderup, Corporate Tax Systems, Multinational Enterprises, and Economic Integration, July 2004

1242 Vankatesh Bala and Ngo Van Long, International Trade and Cultural Diversity: A Model of Preference Selection, July 2004

1243 Wolfgang Eggert and Alfons J. Weichenrieder, On the Economics of Bottle Deposits, July 2004

1244 Sören Blomquist and Vidar Christiansen, Taxation and Heterogeneous Preferences, July 2004

1245 Rafael Lalive and Alois Stutzer, Approval of Equal Rights and Gender Differences in Well-Being, July 2004

1246 Paolo M. Panteghini, Wide vs. Narrow Tax Bases under Optimal Investment Timing, July 2004

1247 Marika Karanassou, Hector Sala, and Dennis J. Snower, Unemployment in the European Union: Institutions, Prices, and Growth, July 2004

1248 Engin Dalgic and Ngo Van Long, Corrupt Local Government as Resource Farmers: The Helping Hand and the Grabbing Hand, July 2004

1249 Francesco Giavazzi and Guido Tabellini, Economic and Political Liberalizations, July 2004

1250 Yin-Wong Cheung and Jude Yuen, An Output Perspective on a Northeast Asia Currency Union, August 2004

1251 Ralf Elsas, Frank Heinemann, and Marcel Tyrell, Multiple but Asymmetric Bank Financing: The Case of Relationship Lending, August 2004 